\title{
Assessing the Effect of Schooling on Earnings Using a Social Experiment*
}

\author{
Costas Meghir ${ }^{\dagger}$ and Marten Palme $e^{\ddagger}$
}

January 26, 2000

\begin{abstract}
The implementation of the 1950 Swedish comprehensive school reform was preceded by a unique social experiment. During this experiment between 1949 and 1962 the new school system was implemented in stages. This allows us to study the same cohort of individuals going through two different school systems, one of them implying at least one year of prolonged compulsory schooling, in a very similar environment. We use this exogenous variation in educational outcomes to estimate the average returns to education allowing for heterogeneity in the returns across individuals. We also use an ability measure (IQ scores and grades obtained at age 12 or 13) to allow for heterogenous returns to observed ability.
\end{abstract}

\footnotetext{
${ }^{*}$ We thank Jerome Adda, Orazio Attanasio, Anders Björklund, Lorraine Dearden, Christian Dustmann, Lars-Erik Öller, Chris Taber as well as participants on seminars at University of Umeå, Uppsala University, Tinbergen Institute in Amsterdam, The Trade Unions Institute for Economic Research in Stockholm and IIES at Stockholm University for comments; We are also grateful to Jan O. Jonsson for first informing us about the nature of the experiment preceding the school reform that we analyze in this paper. Finally, we would like to thank the Department of Education, University of Gothenburg and the Institute for Social Research at Stockholm University for letting us use their data. Marten Palme acknowledges financial support from The Swedish Council for Social Research. Costas Meghir acknowledges financial support from the ESRC via the CFP at the IFS.

${ }^{\dagger}$ Department of Economics, University College London, Gower Street, London WC1E 6BT, UK. E-mail: C.Meghir@ucl.ac.uk.

${ }^{\ddagger}$ Stockholm School of Economics, Box 6501, SE-113 83 Stockholm, Sweden. E-mail: Marten.Palme@hhs.se.
} 


\section{Introduction}

The economic rate of returns to education is of central importance for both private and public investment decisions in education. Yet, there is very little consensus both on the range of the true returns to education and on the appropriate method to measure it. The methodological difficulties originate from the fact that education is not randomly assigned to the individuals in the population. A series of recent studies (see Angrist and Krueger, 1991 and 1992, Butcher and Case, 1994, Card, 1993, Harmon and Walker, 1995, Kane and Rouse, 1993) have tried to overcome these difficulties by using the instrumental variable approach and use different sources of exogenous variation in individual educational attainments. A common characteristic of many of these studies has been that the estimates of the returns to education have increased, after allowing for the endogeneity of schooling. Card (1994) has shown that this may be an artifact of failing to take into account that the returns to education may be heterogeneous across different individuals. ${ }^{1}$

In 1950 the Swedish parliament decided to extend the compulsory schooling from 7 or 8 years (depending on the municipality) to a 9 year comprehensive school with a centrally decided curriculum. What makes this reform of general interest in the context described in the previous paragraph is that it was preceded by a unique nationwide social experiment between 1949 and until the new school system was finally implemented in 1962. In this experiment, the new comprehensive school was implemented gradually, by municipality, in Sweden's 1,031 municipalities. The experiment allows us to compare the labour market outcome of a comparatively large cohort of individuals going through two different school systems, with different amounts of compulsory schooling, in a very similar environment. The effect of compulsory schooling can, thus, be isolated from the effect of macroeconomic shocks, cohort effects and the effect of work experience.

\footnotetext{
${ }^{1}$ See also Lang (1993) for a complete description of the model.
} 
We will consider individual heterogeneity in returns to education (due to unobservables) by using a random coefficients model (see Heckman and Robb, 1985). The main result from this model can be interpreted as an estimate of the average economic returns to schooling. The approach we use follows from Willis and Rosen (1979) and has also been used by Björklund and Moffitt (1987) when estimating the returns to training. Thus we allow the returns to education or to qualification level to vary by both observable and unobservable characteristics. In our model individuals can self-select by comparative advantage.

We use two different data-sets for the empirical analysis of this study. The first data-set is the Individual Statistics survey. ${ }^{2}$ This is a random sample of about 10 percent of Swedish individuals born in 1948 or 1953 and were obtained when the individuals were in sixth grade (aged 12 or 13), i.e. in 1961 and 1966 respectively. Earnings from labour in 1993 for each individual were obtained by matching the sample with tax registers. Information on qualification level were obtained from the National Education Register. What makes this data-set particularly useful for the purposes of this study is that, in addition to education reform assignment, it contains results from three different IQ tests as well as information on grades in different subjects taught in school. As these ability measures were obtained at a time when each student had received equal quantity of schooling. ${ }^{3}$

Using this data-set we follow two approaches. In the first we use the reform structure as a source of exogenous variation to estimate the effects of educational qualifications on earnings and to test for the exogeneity of the educational choice. We also exploit the availability of the large number of detailed ability indicators to consider the extent to which the returns to qualifications are affected by observable ability. We find that there is a complementarity between education and ability and

\footnotetext{
${ }^{2}$ This data-set is provided by the Department of Educational Science at the University of Gothenburg, see e.g. Härnqvist and Svensson (1973).

${ }^{3}$ See Angrist and Krueger (1998) on the importance of using ability measures that are not outcome variables.
} 
that there is a return to high ability at all education levels, i.e. more able individuals have an absolute and comparative advantage for higher education.

The second data-set is the Swedish Level of Living survey. ${ }^{4}$ There are two reasons for also using this data-set. First, this data-set contains measures of number of years of schooling, rather than qualification levels. This enables us to obtain a benchmark for comparing our results with those of other studies from different countries. Second, in this data set, we know the place of birth of the individual. This will allow us to construct an instrument based not on where they went to school but on where they were born. This avoids potential biases that could arise due to selective migration based on preferences of school system.

The paper is organized as follows. Section 2 gives a description of the Swedish education system and the 1950 education reform. Section 3 presents the econometric model. Section 4 describes the data-sets. Section 5 discusses sources of possible endogeneity in the instruments used. Section 6 presents the results and Section 7 concludes.

\section{The 1950 Education Reform}

Sweden has a long history of compulsory schooling. The first compulsory public school system was introduced already in 1842. Since then, the education program has been expanded to include an increasing number of school years. The most important reform of the Swedish school system after 1900 is the implementation of a comprehensive, compulsory 9 year basic education with a centrally decided curriculum for all schools in Sweden. This reform was decided by the Swedish parliament in 1950.

The primary aims of the 1950 educational reform were:

(1) To extend the education of the least skilled. The number of compulsory years of education was extended from seven to nine years. In 1949, about 65 per cent of individuals did not complete any education beyond primary school (see Erikson and

\footnotetext{
${ }^{4}$ This survey were obtained by the Swedish Institute for Social Research at Stockholm University.
} 
Jonsson, 1993).

(2) To facilitate the transition to higher education. Before the reform, it was decided very early, already at the age of twelve or thirteen, who could qualify for vocational school, which was the dominant pathway to secondary and higher education.

(3) To promote equality of opportunity. The comprehensive school is more strictly regulated from the central government; this is thought to prevent differences between areas with different geographical or socio-economic location.

Although the principles of the new schooling system were decided in 1950 it was not fully implemented until 1962. Between 1949 and 1962 a nationwide experiment with the new school was conducted. ${ }^{5}$ During these years the new school operated in parallel with the pre-reform school system. The aim of the experiment was to evaluate the principles of the new school proposed by the parliamentary committee and also to outline several details in the curriculum of the new school (see Marklund, 1981, p 25).

It was decided that the new school system should be implemented in entire municipalities rather than in separate schools in the experiment. At the time of the first year of the experiment, in 1949, Sweden consisted of 2,501 municipalities. To be selected as a municipality to implement the new school system in the first years of the experiment two requirements had to be fulfilled:

(1) Eight years of compulsory schooling should already have been implemented in the municipality.

(2) The demographic structure of the municipality should be such that a continuous flow of pupils could enter into the new school system.

The parliamentary committee selected 264 municipalities which they found suitable for implementing the new school system in the first year of the experiment. Of these, 144 responded that they were interested in doing that. Of these, 14 were selected to implement the new school in the first year of the experiment. The rationale for choosing these particular municipalities, was that they were considered to be rep-

\footnotetext{
${ }^{5}$ This experiment is described in detail in Marklund (1981).
} 

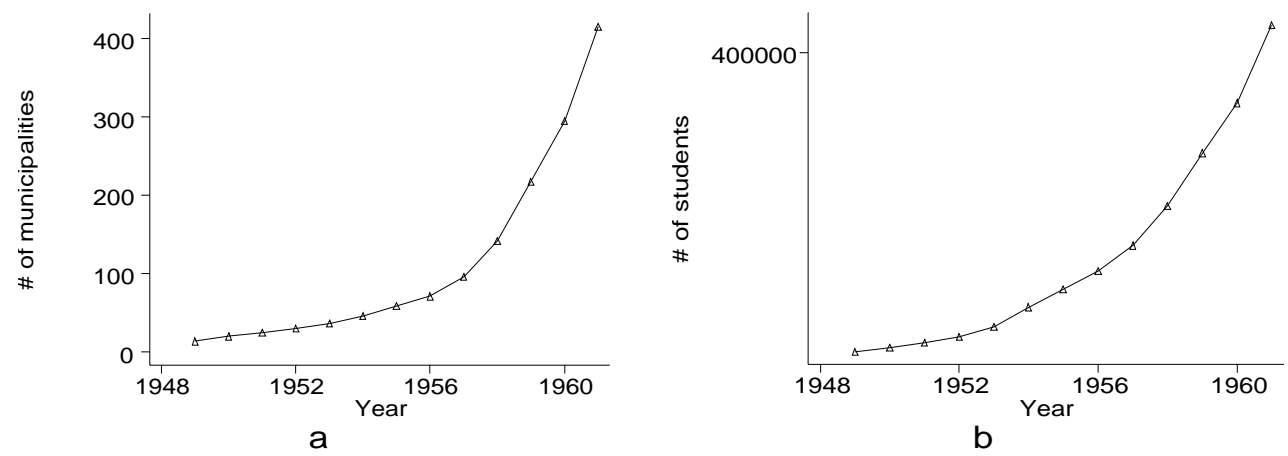

Source: Table 11 at page 97 in Marklund (1981).

Table 1: Quantitative evolvement of the experiment between 1949 and 1962. (a) Number of municipalities which implemented the new school. (b) Number of students assigned to the new school.

resentative, demographically and geographically, for the entire country. This method of choosing in which municipality the new school system should be implemented was retained throughout the entire experiment. It should, however, be noted that the politicians in each municipality had the final decision on implementing the new school in their municipality.

Figure 1 shows the evolution of take-up of the experiment between 1949 and 1961 . Figure $1 \mathrm{a}$ shows the number of municipalities and Figure $1 \mathrm{~b}$ the number of students entering the experiment. Figure 1a uses the division of municipality areas from 1952, when Sweden was divided into 1,031 municipalities. It can be seen that the new schooling system was implemented in almost 50 per cent of the municipalities in 1961 - the year before the new school was implemented nationwide.

Some municipalities implemented the new school from the first grade only, while others implemented it directly in all grades up to the fifth. This means that the last students following the pre-reform system finished compulsory school in the beginning of the 1970s.

In order to offset the financial burden for the families to have their children in school one or two extra years, child allowances paid by the central government were 
introduced, and students from families in financial difficulties were offered government scholarships for those in the reformed system.

\section{Empirical Specification and estimation}

The estimation of the returns to education exploits the fact that those assigned to the reform had higher educational outcomes (as we show later) for exogenous reasons. Hence broadly speaking, our results are based on comparing the earnings of those who were assigned to the reform to those who were not and relating this difference to the different educational outcomes induced by the reform assignment. The power of our approach is based on the fact that we can compare the outcomes of individuals at the same point in time and belonging to the same cohort, while going through different education systems. In what follows we formalise this idea within the context of two different models.

We consider a $\log$ annual earnings $\left(\ln w_{i}\right)$ equation for individual $i$ of the form:

$$
\ln w_{i}=\beta^{\prime} x_{i}+\sum_{l=2}^{L}\left(\rho_{l}+\varepsilon_{i l}\right) S_{i l}+\varepsilon_{i 1}
$$

where $S_{i l}$ is an indicator denoting the highest qualification out of $L$ possible levels, attained by the individual. The default level of education is denoted by $S_{i 1}$ (the omitted category). If level $l$ has been achieved only $S_{i l}$ is equal to one, all other indicators being set to zero. The characteristics affecting the level of earnings are $x_{i}$ and they include ability type variables. The average returns to achieving schooling level $l$ relative to schooling level 1 , is $\rho_{l}$. The unobservable $\varepsilon_{i l}$ represents the heterogeneity in the returns to schooling level $l$ and $\varepsilon_{i 1}$ represents unobserved characteristics affecting the level of the wage, as well as measurement errors in earnings. ${ }^{6}$

There are two potential channels of bias if OLS is used to estimate 3.1. The first is the standard ability bias problem which has been discussed extensively and in 3.1

\footnotetext{
${ }^{6}$ We also consider heterogeneity in the returns due to observable ability variables.
} 
is due to the correlation of overall unobserved ability $\varepsilon_{i 1}$ with the level of schooling achieved $\left(S_{i l}\right)$.

The second source of bias which has not been investigated as much is the one arising from the heterogeneity in the returns (i.e. $\varepsilon_{i l}$ ). If $\varepsilon_{i l}$ is known to the individuals they will self-select to the appropriate education level by comparative advantage as shown by Willis and Rosen (1979). As pointed out by Heckman and Robb (1985) the standard Instrumental Variables method (IV) does not provide consistent estimate of the average population returns $\rho_{l}$ in this case. ${ }^{7}$ To see this, suppose that we have an instrument $r_{i}$ with sufficient predictive power for schooling level (i.e. satisfying the rank condition) and uncorrelated with the unobserved returns $\varepsilon_{i 1}$ and $\varepsilon_{i l}$, i.e. : $E\left(\varepsilon_{i 1} \mid x_{i}, r_{i}\right)=0$ and $E\left(\varepsilon_{i l} \mid x_{i}, r_{i}\right)=0$. However, $S_{i}$ may depend on the $\varepsilon_{i l}$ through the optimal choice of education. Hence the conditional covariance of $S_{i}$ and $\varepsilon_{i l}$ will not be zero, i.e. $E\left(S_{i} \varepsilon_{i l} \mid x_{i}, r_{i}\right) \neq 0$; The instrument is thus correlated with the error term which contains $S_{i l} \varepsilon_{i l}$ and hence IV will be inconsistent for the average treatment effect in the population $\left(\rho_{l}\right)$.

Addressing this issue, Imbens and Angrist (1994) developed an interpretation of IV in such models (Local Average Treatment Effects or LATE). Under this interpretation (and given a further assumption) IV identifies the effect of achieving a particular level of education for those induced to obtain it as a result of the particular reform (the switchers). This may well be the parameter of interest in certain circumstances, but not if we are interested in the average returns to education in the population. Of course if $\varepsilon_{i l}$ is not known by the individual when the schooling choice is made, then it is not correlated with the choice of schooling and the standard IV framework identifies the average returns to a randomly assigned individual.

To solve the problem we need to model explicitly the relationship between the unobserved returns and schooling, treating the model in equation 3.1 as a switching

\footnotetext{
${ }^{7}$ See Heckman, Lalonde and Smith (1998) for a complete discussion of this issue.
} 
regression model. ${ }^{8}$ We denote by $S_{i}$ the vector of $S_{i l}$. Thus consider the expectation of $\log$ wages conditional on $x_{i}, S_{i}$, and the exogenous instruments, i.e.

$$
E\left(\ln w_{i} \mid q_{i}, S_{i}\right)=\beta^{\prime} x_{i}+\sum_{l=2}^{L} \rho_{l} S_{i l}+\sum_{l=2}^{L} E\left(\varepsilon_{i l} \mid q_{i}, S_{i}\right) S_{i l}+E\left(\varepsilon_{i 1} \mid q_{i}, S_{i}\right)
$$

where $q_{i}$ represents all the exogenous variables including $x_{i}$ and the instruments. We now assume that $E\left(\varepsilon_{i l} \mid q_{i}, S_{i l}=1\right)=\delta_{l} \lambda_{l}\left(q_{i}^{\prime} \gamma\right)$, where $\lambda_{l}\left(q_{i}^{\prime} \gamma\right)$ is a generalised residual from an ordered probit model of education. A different reduced form model for the highest education level attained is estimated for those who went through the reform and those who did not; hence both the slope coefficients and the thresholds in the ordered probit are allowed to vary with the reform status. The method we use is justified under the assumption that one single index $\left(q_{i}^{\prime} \gamma\right)$ affects education choices. Under this single index assumption only one exclusion restriction is required. Cameron and Heckman (1998) provide conditions under which an ordered probit is a valid representation of education choices. ${ }^{9}$

The way we estimate the reduced form education choice model allows for the possibility that the reforms affected the attainment of some education level but not others. Thus, suppose the assignment to the reform affects attainment of some education levels but not of others. In this case we can identify the relative returns between the education levels affected by the reform, but we cannot identify the returns to other levels when education choices are endogenous for wages. This is particularly relevant when we consider estimating the returns to education using exogenous policy reforms. Often education reforms are targeted to the lower end of the education levels. To use

\footnotetext{
${ }^{8}$ see Quandt, 1972, Willis and Rosen, 1979, Heckman and Robb, 1985 and Björklund and Moffitt, 1987

${ }^{9}$ The assumption of an ordered probit is not strictly compatible with a general Roy model of self selection. In this case dealing with the endogeneity problem requires a multi index model of education choice. The resulting identification issues are an important question which we intend to deal with in the next version of the paper. However, in view of our results, we believe that the current representation captures the main sources of endogeneity. The recent literature on the returns to education has circumvented such issues by assuming that only years of education matter.
} 
such reforms to identify the returns to higher levels of education, we either need to establish that post-reform the likelihood of attaining higher levels of education increased or we need to impose functional form assumptions such that wages only depend on the number of years of education in say a linear fashion. ${ }^{10}$

Estimation takes place in two stages. First, we estimate the ordered probit for educational achievement and construct an estimate of $\lambda_{l}\left(q_{i}^{\prime} \gamma\right)$. At the next stage we estimate

$$
\ln w_{i}=\beta^{\prime} x_{i}+\sum_{l=2}^{L} \rho_{l} S_{i l i}+\sum_{l=1}^{L} \delta_{l} \widehat{\lambda}_{i l} S_{i l}+u_{i}
$$

Applying OLS on 3.3 provides us with consistent estimates of the average return to each level of education. The standard errors need adjusting for estimated regressor bias. In all cases the excluded instrument is the assignment to the reform and interactions of this variable with other controls (all of which are included among the $x_{i}$ ). These include county of residence, cohort effects and ability variables. In fact with data on more than one cohort (as in our case) it is possible to test that the reform had no other effect on wages other than through its effect on the amount of schooling, so long as the reform had different effects across the cohorts and so long as the returns to education are common across cohorts. Finally, note that in the context of this model the equivalent of instrumental variables is obtained by assuming the coefficients $\delta_{l}$ are constant across education levels $\left(\delta_{l}=\delta\right.$ for all $l$ ).

To sum up, this specification differs in two important respects from the standard model which includes years of education, used by e.g. Angrist and Krueger (1991) and Harmon and Walker (1995) who also use institutional differences in compulsory schooling as exogenous variation in individual educational attainments. First, we allow explicitly the returns to education to be heterogeneous across individuals and

\footnotetext{
${ }^{10}$ It may well be that further identifying information can be obtained by exploiting the dependence restrictions between the education groups. Quite clearly not all paths to particular education level are possible and this could be used for further identifying information. However, this would require estimating a structural model of education choice which we do not pursue here.
} 
provide an estimation approach for the average population returns to schooling. Our model allows for self selection to different education levels by comparative or absolute advantage. Second, it allows for non-linear returns, by using the level of education achieved, rather than just the years of education. ${ }^{11}$ The functional form restrictions implied by linearity are of particular importance when institutional differences in compulsory schooling are used as a source of exogenous variation. It is unlikely that compulsory schooling laws has an impact on assignment to all levels of education. That is, the identification of the causal effect of higher levels of education on earnings in the standard model may rely heavily on the assumption of linearity.

However, using a separate smaller data set, we also estimate a model which is linear in the years of education $\left(e d_{i}\right)$ but where the returns differ across individuals:

$$
\ln w_{i}=\beta^{\prime} x_{i}+\theta e d_{i}+\varepsilon_{i}^{1} e d_{i}+\varepsilon_{i}
$$

where $x_{i}$ represents observed exogenous characteristics which determine earnings and where $\left(\theta+\varepsilon_{i}^{1}\right)$ is the individual specific return to education. ${ }^{12}$

Allowing for the possibility that $\varepsilon_{i}^{1}$ is in the information set of the individual when the education choice is made we can express expected wages, conditional on the reform and on the education choice as

$$
E\left(\ln w_{i} \mid r_{i}, e d_{i}, x_{i}\right)=\beta^{\prime} x_{i}+\theta e d_{i}+\delta_{1} v_{i} e d_{i}+\delta_{2} v_{i}
$$

where $v_{i}$ represents the error term in a linear regression of education on the exogenous variables of the model $x_{i}$ and the reform indicator, which acts as the instrument. ${ }^{13}$ Substituting $v_{i}$ for an estimated residual and applying OLS to the above provides us with consistent estimates of $\theta$.

The specification 3.4 highlights the other main difference of our model from the

\footnotetext{
${ }^{11}$ On this issue for the US see Card and Krueger, 1992 and Heckman, Layne-Farrar and Todd, 1996.

${ }^{12}$ This model is consitent with an equilibrium in a simple human capital model of education choice if individuals face liquidity constraints when choosing education levels.

${ }^{13}$ i.e. $v_{i}=e d_{i}-E\left(e d_{i} \mid x_{i}, r_{i}\right)$
} 
literature; standard IV in this context would be identical to setting $\delta_{1}$ to zero. ${ }^{14}$ In this case (ignoring the $x_{i}$ ) the estimate of $\theta$ is simply the difference in the average log wage between those who were assigned to the reform and those who were not divided by the difference in average years of education.

\section{Data}

We use two different data-sets in the empirical analysis. For the main analysis, the assessment of the rate of returns to qualification levels, we use data from the Individual Statistics (IS) project of the Institute for Education at the University of Gothenburg. ${ }^{15}$ For the analysis of the rate of returns to years of education, we use data from the Swedish Level of Living Survey (SLLS) provided by the Swedish Institute for Social Research at Stockholm University. ${ }^{16}$

\subsection{The Individual Statistics Data-set}

The IS project has produced six separate data-sets each consisting of approximately $10 \%$ of the birth cohorts 1948, 1953, 1967, 1972, 1977 and 1982 . We use the surveys for the 1948 and 1953 cohorts as these are the only ones affected by the experiment. Both the 1948 and 1953 cohort samples are systematic samples from the National Swedish Register of Students: All students born the 5th, 15th or 25th in each month were selected to be included in the samples. Since there is no reason to believe that those who are born on the 5th, 15th or 25th are in any respect different from those born on other dates in each month, these two samples can be seen as purely random samples from the population of individuals born in Sweden. ${ }^{17}$ As each month consists of about 30 days, these samples include about 10 per cent of the total 1948 and 1953

\footnotetext{
${ }^{14}$ See Garen (1984), Heckman and Vytlacil (1998) and Dustmann and Meghir (1999) for the econometric justification.

${ }^{15}$ See Härnqvist and Svensson (1973) for a detailed description of the surveys.

${ }^{16}$ See Erikson and $\AA$ berg (1987) for a detailed description of this survey.

${ }^{17}$ Probably, not even astrological theories (!) can predict any differences between those who are born these particular dates in each month and the rest, since they are spread out over all months over the year.
} 
birth cohorts in Sweden respectively. The absolute number of students born on these particular dates, i.e. the potential sample sizes, was 12,166 for the 1948 cohort and 10,723 for the 1953 cohort. With a rate of non-response for the 1948 survey of about 1.8 per cent and 7.4 per cent for the 1953 cohort survey, the final sample sizes were 11,950 for the 1948 birth cohort and 9,923 for the 1953 cohort.

The 1948 cohort survey was obtained in the spring of 1961 and the 1953 cohort survey in the spring of 1966. This means that the respondents were 12 or 13 years of age and most of them in sixth grade in compulsory school by the time of the survey. This means that those who followed the pre-reform school system were in the sixth grade in the elementary school - the year before they were split-up in either the seventh grade in elementary school or the first grade in vocational school. Those who followed the new, pre-reform school system were in the sixth grade in the comprehensive school.

In 1961 the experiment with the new comprehensive school was still in progress and, as can be seen in Section 2, almost 50 per cent of the municipalities had implemented the new school. However, as some municipalities only implemented the new school from the first grade, only about 35 per cent of the students in our data-set were assigned to the new school (see the descriptive statistics in the Appendix). In 1966 all municipalities had implemented the new school, although starting in different grades, and about 80 per cent of the students in the survey were assigned to the new school system.

The data-sets consist of four main parts: (1) Information on the student's social background, socio-economic situation, leisure activities and plans for future studies; (2) Results from IQ and achievement tests; (3) Register information on the students performance and type of school; (4) Annual earnings obtained from the 1993 Swedish tax registers as well as information obtained from the education registers also from 1993.

Information on levels of education were obtained from the so called SUN-code from the National Education Register. This code also provides information on the field of 


\begin{tabular}{|c|c|c|}
\hline Level & Description of the Schooling Level & $\begin{array}{l}\text { Average Number of } \\
\text { Years of Schooling }\end{array}$ \\
\hline 1 & Pre-reform compulsory school (7 or 8 years) & 7.33 \\
\hline 2 & $\begin{array}{l}\text { Post-reform coprehensive (compulsory school) } \\
\text { or pre-reform junior secondary school }\end{array}$ & 9.62 \\
\hline 3 & $\begin{array}{l}\text { Upper secondary school } \leqslant 2 \text { years, } \\
\text { mainly vocational school }\end{array}$ & 10.39 \\
\hline 4 & $\begin{array}{l}\text { Upper secondary school } \geqslant 3 \text { years, Gymnasium, } \\
\text { sixth form of a comprehensive school (UK), senior high school (US) }\end{array}$ & 12.19 \\
\hline 5 & $\begin{array}{l}\text { Post upper secondary school } \leqslant 2 \text { years, shorter college } \\
\text { educations (US), e.g. education for nurses or elementary school teachers }\end{array}$ & 13.87 \\
\hline 6 & $\begin{array}{l}\text { Post upper secondary school } \geqslant 3 \text { years, education in e.g. } \\
\text { buissiness administration, law, engineering or medicine }\end{array}$ & 16.77 \\
\hline 7 & Ph.D. or licentiate degree at a University & 19.57 \\
\hline
\end{tabular}

Note: Estimates of the average number of years of schooling for each level of education are obtained from the Swedish Level of Living survey for the cohorts born between 1945 and 1955.

Table 1: Short descriptions of each education level and estimates of average number of years of schooling for each level.

study for each individual. In this study, however, we use the information on seven educational levels only. These levels are briefly described in Table 1. Table 1 also contains estimates of the average number of years of schooling corresponding to each education level.

Given the way the information is collected, and as we use comparatively broad categories for levels of education, there is very little scope for measurement error in education. This is important, particularly given concerns that when we include controls for observed ability we reduce the signal from the education variable to relative to the measurement error variance, thus biasing the education effect downwards (see Griliches, 1977). In the Appendix we describe the variables used in this study from each of these blocks of the data-sets. The Appendix also gives descriptive statistics from the samples we use of the included variables.

As is evident from the description in the Appendix, the IS survey contains several useful measures of intellectual ability. In order to obtain a flexible specification we 


\begin{tabular}{lr}
\hline \hline All & 21,877 \\
Men & 11,142 \\
Employees in 1993 & 8,381 \\
With valid SUN code & 8,370 \\
With completed tests & 7,985 \\
\hline
\end{tabular}

Table 2: Number of individuals remaining in the sample after different stages in the sample selection. 1948 and 1953 cohort IS surveys combined.

transformed the test scores into decile groups and then generated indicator variables for each decile group and each test. This procedure, however, produces a large number of variables. As these variables measure similar individual properties they are highly correlated with each other. Hence we have performed a principal component analysis on the indicator variables from the ability measures. This principal component analysis is described in the Appendix.

To obtain the samples used in the estimations a number of selections were made. Table 2 shows the number of individuals remaining after each step in this sample selection. First, we have restricted the sample to men. In 1993 the individuals in the 1948 cohort survey are aged 45 and those from the 1953 cohort survey are aged 40 . In these ages most men work full time. We also know that the unemployment rate among men in these ages are fairly low. Second, since we require complete records of labour earnings we exclude non-workers, the self employed and seamen.

As can also be seen in Table 2, 385 individuals did not complete one or more of the IQ or achievement tests. However, as we combine all ability measures using principal component analysis, and as we have results from at least one test as well as grades for these individuals, we are able to construct ability measures for these individuals as well.

\subsection{The Swedish Level of Living Survey}

The Swedish Level of Living Survey consists of samples from four different points in time: 1968, 1974, 1981, and 1991. Each of these are random samples of Swedish indi- 
viduals in ages between 16 and 75 years and the sample size is about 6,000 individuals for each sample, i.e. 0.1 per cent of the Swedish population in this age group. The rate of non-response is about 18 percent.

We use the same measure for labour earnings as in the IS survey, i.e. taxed income from labour obtain from taxed registers matched with the SLLS survey, in order to use comparable measures as for the IS survey. We use primarily the 1991 survey. However a small fraction of non-responders in the 1991 survey (who responded in 1981) were collected from the 1981 survey. Earnings in all cases is collected from the 1991 tax register.

Although the SLLS data-set does not contain any explicit measure of ability, it contains two variables that cannot be obtained in the IS survey. First, in addition to the qualification level variable of the IS survey, it contains a self reported measure of number of years of schooling. This variable not only enables us to estimate the economic returns to the number of years of schooling when using this data-set directly, it can also be used to estimate the average number of years of schooling corresponding to each qualification level in the IS survey. That is, we can get an assessment of the returns to number of years of schooling corresponding to the estimates of returns to qualification levels obtained from the IS survey.

The second variable which may be obtained in the SLLS survey, but not in the IS survey, is municipality of birth. With this we can construct an instrument based on the time at which the municipality implemented the reform. This instrument gets round the potential problem of families moving to the municipality with the preferred educational system. If preferences for the education system are correlated with unobserved child ability, such mobility (although small in Sweden) could make the reform indicator endogenous for wages. The downside of using such an instrument is that it is less informative (but not much as we shall see) since it does not allocate people to the system they did follow but to the system they would have followed if 
their family stay in the municipality where they are born. ${ }^{18}$

To obtain the sample used in the estimation, we have made several selections. We have excluded farmers, self employed, students, members of the military as well as individuals who are born outside Sweden. We have restricted the sample to individuals born between 1945 and 1955 and, as we did in the analysis on the IS survey, we have restricted the sample to men. When these selections were made, 427 observations remained in the data-set. The small sample size and the absence of the ability indicators makes the use of the IS cohorts a particularly attractive alternative. Appendix B contains descriptive statistics for the included variables.

\section{Is Assignment to the Education Reform a Legitimate In- strument?}

The source of exogenous variation we use for identification is assignment to the education reform. Needless to say, it is required that reform assignment is exogenous for earnings. Below we provide, to the extent possible, some evidence based on observable indicators, that this instrument is not related to individual productivity.

The municipalities that implemented the reform early were not randomly chosen in a strict sense. The committee who implemented the reform, at least in the first years of the implementation, tried to get the reform implemented by a "representative" set of municipalities. However, the reform was not implemented during the experimental period, in municipalities that did not agree to it. It is, thus, possible that municipalities consisting of citizens that place a high emphasis on education voted for politicians that were more willing to implement the reform early. It can be hypothesized that this enthusiasm for education is correlated with productivity enhancing investments made by parents on children.

On the other hand, the pre-reform system provided voluntary education for the

\footnotetext{
${ }^{18}$ The SLLS survey also contains information on self assessed reform assignment. In about 23 percent of the cases, the imputed and the self-assessed information gave different results.
} 
high achievers. Such streaming was to a large extent abolished after the reform. Thus, parents of high ability pupils may have preferred the preservation of the previous system and may have acted to force a delay. To address the issue that the timing of the implementation of the reform is correlated with ability we compare ability indicators for those who went through the reform in those who did not, in the two cohorts.

The data-set contains information from individual IQ-tests as well as results from several tests on knowledge in different subjects taught at school. ${ }^{19}$ The results from this comparison, i.e. the average scores on the different test for the two sub-groups, are shown in Table 1. As can be seen in Table 1, the average results on these tests are very similar, although one may argue that the municipalities that participated early on had marginally more able students. In most cases the differences are not statistically significant. Of course, we will control for the differences in observed ability. Our presumption is that these results lend support to the idea that reform assignment is not correlated with unobserved ability.

\begin{tabular}{|c|c|c|c|c|c|c|c|c|}
\hline & \multicolumn{4}{|c|}{1948 survey } & \multicolumn{4}{|c|}{1953 survey } \\
\hline & \multicolumn{2}{|c|}{ Women } & \multicolumn{2}{|c|}{ Men } & \multicolumn{2}{|c|}{ Women } & \multicolumn{2}{|c|}{ Men } \\
\hline & $\begin{array}{l}\text { Pre- } \\
\text { reform }\end{array}$ & $\begin{array}{l}\text { Post- } \\
\text { reform }\end{array}$ & $\begin{array}{l}\text { Pre- } \\
\text { reform }\end{array}$ & $\begin{array}{l}\text { Post- } \\
\text { reform }\end{array}$ & $\begin{array}{l}\text { Pre- } \\
\text { reform }\end{array}$ & $\begin{array}{l}\text { Post- } \\
\text { reform }\end{array}$ & $\begin{array}{l}\text { Pre- } \\
\text { reform }\end{array}$ & $\begin{array}{l}\text { Post- } \\
\text { reform }\end{array}$ \\
\hline IQ, Opposites & $\begin{array}{c}22.2 \\
(0.15)\end{array}$ & $\begin{array}{c}22.8 \\
(\mathbf{0 . 2 0})\end{array}$ & $\begin{array}{c}22.1 \\
(0.14)\end{array}$ & $\begin{array}{c}22.4 \\
(0.20)\end{array}$ & $\begin{array}{c}23.3 \\
(0.26)\end{array}$ & $\begin{array}{c}24.1 \\
(0.12)\end{array}$ & $\begin{array}{c}22.3 \\
(0.26)\end{array}$ & $\begin{array}{c}23.8 \\
(0.12)\end{array}$ \\
\hline IQ, Folding & $\begin{array}{c}20.0 \\
(\mathbf{0 . 1 4})\end{array}$ & $\begin{array}{c}20.7 \\
(0.20)\end{array}$ & $\begin{array}{c}21.5 \\
(0.15)\end{array}$ & $\begin{array}{c}22.3 \\
(0.21)\end{array}$ & $\begin{array}{c}20.9 \\
(0.26)\end{array}$ & $\begin{array}{c}21.6 \\
(0.13)\end{array}$ & $\begin{array}{c}21.3 \\
(0.29)\end{array}$ & $\begin{array}{c}22.7 \\
(\mathbf{0 . 1 4})\end{array}$ \\
\hline IQ, Mathematics & $\begin{array}{c}19.0 \\
(0.16)\end{array}$ & $\begin{array}{c}19.1 \\
(0.22)\end{array}$ & $\begin{array}{c}19.5 \\
(0.17)\end{array}$ & $\begin{array}{c}19.8 \\
(0.23)\end{array}$ & $\begin{array}{c}19.5 \\
(0.29)\end{array}$ & $\begin{array}{c}20.3 \\
(0.14)\end{array}$ & $\begin{array}{c}18.9 \\
(0.31)\end{array}$ & $\begin{array}{c}20.6 \\
(0.15)\end{array}$ \\
\hline Reading & $\begin{array}{c}36.7 \\
(0.15)\end{array}$ & $\begin{array}{c}37.2 \\
(0.20)\end{array}$ & $\begin{array}{c}37.4 \\
(0.15)\end{array}$ & $\begin{array}{c}38.1 \\
(0.21)\end{array}$ & - & - & - & - \\
\hline Writing & $\begin{array}{c}53.3 \\
(0.20)\end{array}$ & $\begin{array}{c}53.4 \\
(0.27)\end{array}$ & $\begin{array}{c}50.5 \\
(0.21)\end{array}$ & $\begin{array}{c}51.0 \\
(0.29)\end{array}$ & - & - & - & - \\
\hline Mathematics & $\begin{array}{c}40.0 \\
(0.19)\end{array}$ & $\begin{array}{c}40.1 \\
(0.26)\end{array}$ & $\begin{array}{c}41.7 \\
(\mathbf{0 . 1 9})\end{array}$ & $\begin{array}{c}41.9 \\
(\mathbf{0 . 2 8})\end{array}$ & $\begin{array}{c}33.9 \\
(0.48)\end{array}$ & $\begin{array}{c}34.7 \\
(0.23)\end{array}$ & $\begin{array}{c}34.4 \\
(0.50)\end{array}$ & $\begin{array}{c}37.2 \\
(0.25)\end{array}$ \\
\hline English & $\begin{array}{c}5.7 \\
(0.04) \\
\end{array}$ & $\begin{array}{c}5.9 \\
(0.05) \\
\end{array}$ & $\begin{array}{c}5.2 \\
(0.04) \\
\end{array}$ & $\begin{array}{c}5.4 \\
(0.05) \\
\end{array}$ & $\begin{array}{c}59.1 \\
(0.70) \\
\end{array}$ & $\begin{array}{c}59.6 \\
(0.34) \\
\end{array}$ & $\begin{array}{c}50.4 \\
(0.76) \\
\end{array}$ & $\begin{array}{r}54.2 \\
(0.36) \\
\end{array}$ \\
\hline
\end{tabular}

Table 1: Average test scores. Pre- and post-reform school systems. Men and women. Standard errors in parentheses.

\footnotetext{
${ }^{19}$ We know from earlier studies, e.g. Blackburn and Neumark (1995) or Kjellström (1997), that performance on these kind of tests are correlated with "ability" and probably also with individual returns to education.
} 
Another questions is whether other changes introduced with the reform had any impact on subsequent earnings, over and above their effect on observed educational attainment is an open question. Empirical evaluations of the 1950 school reform have shown ambiguous overall changes in school quality due to the reform (see Marklund, 1981). In our context we can attempt to test the hypothesis that the reform had no impact on earnings other than through the qualification level achieved, by using the fact that we observe two cohorts both of which were split between the two education systems. The power of the test will depend on whether the education reform had differential impact on the two cohorts we are considering. Of course, in the case when we treat the education choice as exogenous, a very powerful test can be obtained. To pre-empt all the evidence suggests that the effects of the reform operated through the amount of education obtained (qualification level achieved) rather through any other indirect channels such as quality changes.

Finally, it may be that municipalities that were more willing to implement the new school system were more likely to be expanding areas and, therefore, to end up being high wage areas. Furthermore, the reformed school system was implemented relatively early on in Stockholm (the largest city in Sweden and where wages are highest). Sweden consists of 24 counties. Except for the counties with large area, but very low population density in the northern parts of Sweden, it is in general possible to commute within each county. The wage rates vary somewhat between counties (see e.g. Westerlund, 1994). Table 2 reports the share of the students assigned to the new school system in each county for the 1948 and 1953 cohort IS-survey respectively. It can be seen that the share of students assigned to the post-reform school system varies a lot between different counties. We thus include local labour market indicators to control for such labour market differences. We are, however, not able to control for selective migration by unobservables. 


\begin{tabular}{|c|c|c|}
\hline & \multicolumn{2}{|c|}{ Share post reform school system } \\
\hline & 1948 survey & 1953 survey \\
\hline Stockholm & $\begin{array}{c}0.599 \\
(0.011)\end{array}$ & $\begin{array}{c}0.915 \\
(0.005)\end{array}$ \\
\hline Uppsala & $\begin{array}{c}0.577 \\
(0.029)\end{array}$ & $\begin{array}{c}0.898 \\
(0.011)\end{array}$ \\
\hline Södermanland & $\begin{array}{c}0.005 \\
(0.003)\end{array}$ & $\begin{array}{c}0.715 \\
(0.026)\end{array}$ \\
\hline Östergötland & $\begin{array}{c}0.233 \\
(0.017)\end{array}$ & $\begin{array}{c}0.947 \\
(0.004)\end{array}$ \\
\hline Jönköping & $\begin{array}{c}0.186 \\
(0.017)\end{array}$ & $\begin{array}{c}0.669 \\
(0.023)\end{array}$ \\
\hline Kronoberg & $\begin{array}{c}0.292 \\
(0.027)\end{array}$ & $\begin{array}{c}0.718 \\
(0.027)\end{array}$ \\
\hline Kalmar & $\begin{array}{c}0.008 \\
(0.005)\end{array}$ & $\begin{array}{c}0.919 \\
(0.011)\end{array}$ \\
\hline Gotland & $\begin{array}{l}0 \\
-\end{array}$ & $\begin{array}{c}0.264 \\
(0.025)\end{array}$ \\
\hline Blekinge & $\begin{array}{c}0.001 \\
(0.001)\end{array}$ & $\begin{array}{c}0.868 \\
(0.020)\end{array}$ \\
\hline Kristianstad & $\begin{array}{c}0.210 \\
(0.019)\end{array}$ & $\begin{array}{c}0.386 \\
(0.022)\end{array}$ \\
\hline Malmöhus & $\begin{array}{c}0.256 \\
(0.014)\end{array}$ & $\begin{array}{c}0.722 \\
(0.015)\end{array}$ \\
\hline Halland & $\begin{array}{l}0 \\
-\end{array}$ & $\begin{array}{c}0.447 \\
(0.027)\end{array}$ \\
\hline Göteborg & $\begin{array}{c}0.453 \\
(0.016)\end{array}$ & $\begin{array}{c}0.790 \\
(0.013)\end{array}$ \\
\hline Älvsborg & $\begin{array}{c}0.098 \\
(0.011)\end{array}$ & $\begin{array}{c}0.761 \\
(0.019)\end{array}$ \\
\hline Skaraborg & $\begin{array}{c}0.442 \\
(0.024)\end{array}$ & $\begin{array}{c}0.831 \\
(0.019)\end{array}$ \\
\hline Värmland & $\begin{array}{c}0.254 \\
(0.019)\end{array}$ & $\begin{array}{c}0.837 \\
(0.017)\end{array}$ \\
\hline Örebro & $\begin{array}{c}0.025 \\
(0.007)\end{array}$ & $\begin{array}{c}0.774 \\
(0.020)\end{array}$ \\
\hline Västmanland & $\begin{array}{c}0.934 \\
(0.012)\end{array}$ & $\begin{array}{c}0.942 \\
(0.004)\end{array}$ \\
\hline Kopparberg & $\begin{array}{c}0.006 \\
(0.003)\end{array}$ & $\begin{array}{c}0.651 \\
(0.025)\end{array}$ \\
\hline Gävleborg & $\begin{array}{c}0.353 \\
(0.021)\end{array}$ & $\begin{array}{c}0.943 \\
(0.011)\end{array}$ \\
\hline Västernorrland & $\begin{array}{c}0.331 \\
(0.021)\end{array}$ & $\begin{array}{c}0.899 \\
(0.014)\end{array}$ \\
\hline Jämtland & $\begin{array}{c}0.788 \\
(0.024)\end{array}$ & $\begin{array}{c}0.944 \\
(0.008)\end{array}$ \\
\hline Västerbotten & $\begin{array}{c}0.453 \\
(0.023)\end{array}$ & $\begin{array}{c}0.884 \\
(0.020)\end{array}$ \\
\hline Norrbotten & $\begin{array}{c}0.465 \\
(0.020) \\
\end{array}$ & $\begin{array}{c}0.887 \\
(\mathbf{0 . 0 1 4})\end{array}$ \\
\hline
\end{tabular}

Table 2: Share of students asssigned to the pre and post reform school system respectively in different local labor markets. Share of students living within less than 20 minutes comuting distance from closest gymnasium or vocational school. Standard errors in parentheses. 


\section{Empirical Results}

We first discuss the results of the reduced form educational choice equations. We then go on by showing the estimates of the economic returns to education. We consider two sets of empirical results. First, those obtained from the Swedish Level of Living survey, which allow us to estimate the returns to number of years of schooling and use the reform assignment indicator based on place of birth rather than self assessed reform assignment. Second, we estimate the returns to qualification levels using the IS survey. Throughout this Section we use abbreviated names for the educational level. More informative description for each level of education are given in Table 1 in Section 4 .

\subsection{The Effects of the 1950 Reform on Educational Attainments}

The identification of the models used in this study to estimate the returns to education relies on the individuals going through the reform having different educational outcomes than those going through the pre-reform system. There are, however, at least two reasons to why it is not obvious that this would be the case. First, it could be that the reform just enforced by law a trend to acquire more education that most individuals would have chosen anyway. As is described in Section 2, there was a trend in Sweden, as in most other industrialized countries, towards a higher education level during the 1950ties and 1960ties. Second, it is possible that the implementation of the reform just enforced regional differences in preferences for education.

There is, however, potentially an effect working in the other direction. As we describe in Section 2, one of the aims of the reform was to facilitate transition to higher education. Therefore, we need to establish the extent to which the reform had knock on effects in the choice of higher educational level. Such an effect is of course also of general importance when evaluating the merits of the educational reform. 


\subsubsection{The effect of the education reform on years of education}

In Table 1 we show regression results for years of education controlling for these other factors. Columns $\mathrm{A}, \mathrm{B}$ and $\mathrm{C}$ show the results using the classification to reform status based on the self reported municipality of schooling. Columns D, E and F are based on the potential reform allocation based on the place of birth. ${ }^{20}$ The results show that the reform had a significant and large effect (of nearly a year) on the average years of schooling, even after controlling for cohort effects and area of residence. The conclusion is valid for both types of indicator for reform status.

\begin{tabular}{|c|c|c|c|c|c|c|}
\hline & $\overline{\mathrm{A}}$ & $\mathrm{B}$ & $\overline{\mathrm{C}}$ & $\overline{\mathrm{D}}$ & $\overline{\mathrm{E}}$ & $\mathrm{F}$ \\
\hline Self-assessed reform status & $\begin{array}{c}1.43 \\
(0.302)\end{array}$ & $\begin{array}{c}1.392 \\
(0.383)\end{array}$ & $\begin{array}{c}0.819 \\
(0.392)\end{array}$ & & - & - \\
\hline Predicted reform status & & - & - & $\begin{array}{c}0.990 \\
(0.308)\end{array}$ & $\begin{array}{c}1.322 \\
(0.393)\end{array}$ & $\begin{array}{c}0.968 \\
(0.378)\end{array}$ \\
\hline Father Vocational & & - & $\begin{array}{c}1.230 \\
(0.413)\end{array}$ & & - & $\begin{array}{c}1.269 \\
(0.412)\end{array}$ \\
\hline Father High School & & - & $\begin{array}{c}1.965 \\
(0.566)\end{array}$ & & - & $\begin{array}{c}1.992 \\
(0.566)\end{array}$ \\
\hline Father University & & - & $\begin{array}{c}4.682 \\
(0.909)\end{array}$ & & - & $\begin{array}{c}4.743 \\
(0.907)\end{array}$ \\
\hline Cohort effects (p-value) & No & Yes $(0.321)$ & Yes $(0.330)$ & No & Yes $(0.064)$ & Yes $(0.152)$ \\
\hline Local labor markets ( $\mathrm{p}$-value) & No & No & Yes $(0.065)$ & No & No & Yes $(0.066)$ \\
\hline
\end{tabular}

Table 1: Reduced form estimates of the impact of the reform on the choice of number of years of schooling.

\subsubsection{The effect of the education reform on qualification levels}

Table 2 shows the share of individuals in the different education levels by reform status and the post reform increase. It is evident from these figures that the there is a significant difference in the lower qualification levels. In education level 4 , Upper secondary school (approximately Senior high school, US; Sixth form comprehensive

\footnotetext{
${ }^{20}$ If the family had not moved then the indicator captures the school system that the child would have gone through.
} 


\begin{tabular}{lccc}
\hline \hline Education level & Pre reform & Post reform & Post reform Increase \\
\hline Basic School & 0.188 & 0.016 & -0.172 \\
& $(0.006)$ & $(0.002)$ & $(0.0063)$ \\
Comprehensive/Junior Secondary & 0.095 & 0.202 & 0.107 \\
& $(0.005)$ & $(0.003)$ & $(0.0058)$ \\
Vocational & 0.256 & 0.291 & 0.035 \\
Upper Secondary & $(0.005)$ & $(0.007)$ & $(0.0086)$ \\
& 0.168 & 0.160 & -0.008 \\
Post Upper Secondary $\leqslant$ years & $0.006)$ & $(0.002)$ & $(0.0063)$ \\
& 0.109 & 0.139 & 0.030 \\
University/College & $0.002)$ & $(0.005)$ & $(0.0054)$ \\
& 0.173 & 0.178 & 0.005 \\
Ph.D. & $(0.006)$ & $(0.003)$ & $(0.0067)$ \\
& 0.012 & 0.015 & 0.003 \\
& $(0.002)$ & $(0.002)$ & $(0.0028)$ \\
\hline
\end{tabular}

Notes: Standard errors in parentheses. 1948 and 1953 cohorts pooled

Source: IS Survey

Table 2: Distribution of qualification level by reform status.

school, UK) and in the two University degree education level groups, there is no significant difference between the educational attainments of those who went through reformed school system compared to the pre-reform group. However, based on this Table the reform seems to have affected school attainment over and above moving pupils from the old to the new minimum level. In particular it has affected positively attendance in the more vocational type streams, such as level 3 and level 5 . There is no apparent effect on attendance to University, as we would expect. We investigate this further below.

The reduced form we use for educational attainment is an ordered probit. In this ordered probit we include all the exogenous variables included in the earnings equation (such as ability, county, father's education and cohort) and we interact all regressors including the thresholds for the ordered probit with the reform indicator. The resulting reduced form allows for the possibility that the reform affected some education levels but not others. At the same time it is a single index model as required 


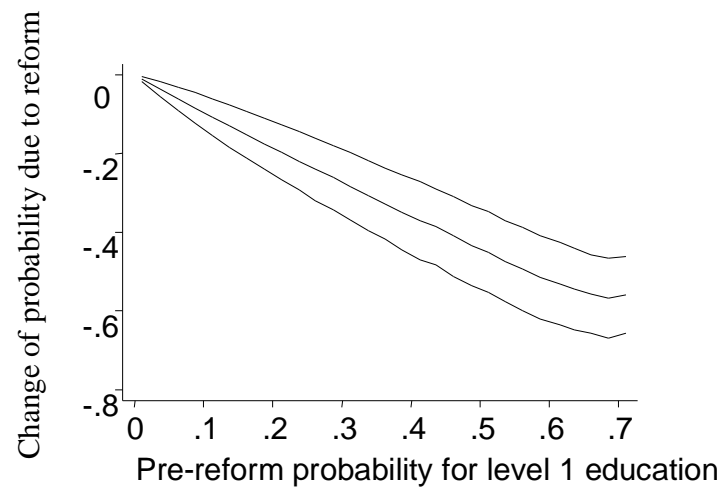

Figure 1: Predicted post-reform change in the probability of obtaining education level 1.

for identification.

The coefficients in the ordered probit are hard to interpret, particularly with the reform indicator interacting with all regressors and the thresholds. We thus present the results graphically. In each of the seven graphs that follow we show the effect of the reform on the change in the probability of attainment of each level, against the pre-reform probability of attaining that level. The pictures also contain a $95 \%$ pointwise confidence interval. The results are presented in figures 1 to 7 .

Level 1 to Level 7 corresponds to the qualification levels in Table 2 and are the highest level of qualification achieved by the individual. The reform had its largest effect at the lowest end, where it was targeted: A large increase in the statutory level of schooling. The effect is large and highly significant, showing that the reform did not just make compulsory the (minimum) schooling that all pupils were already obtaining. However, what is confirmed by these results is that the reform had an effect in the attendance at higher levels of education - particularly those levels that 


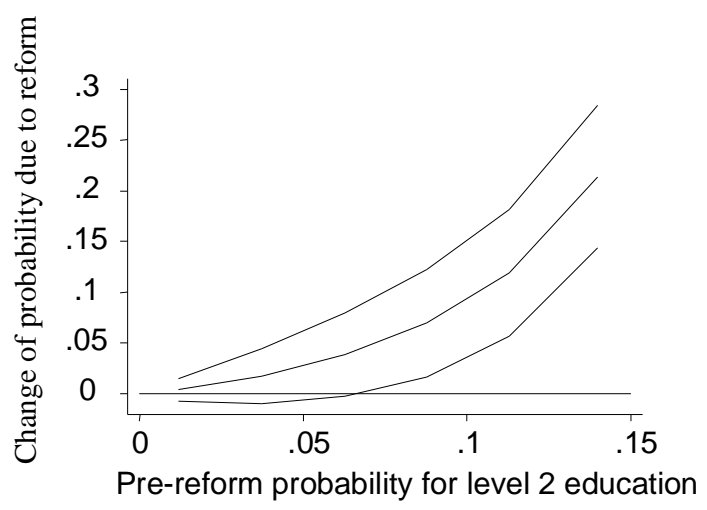

Figure 2: Predicted post-reform change in the probability of obtaining education level 2 .

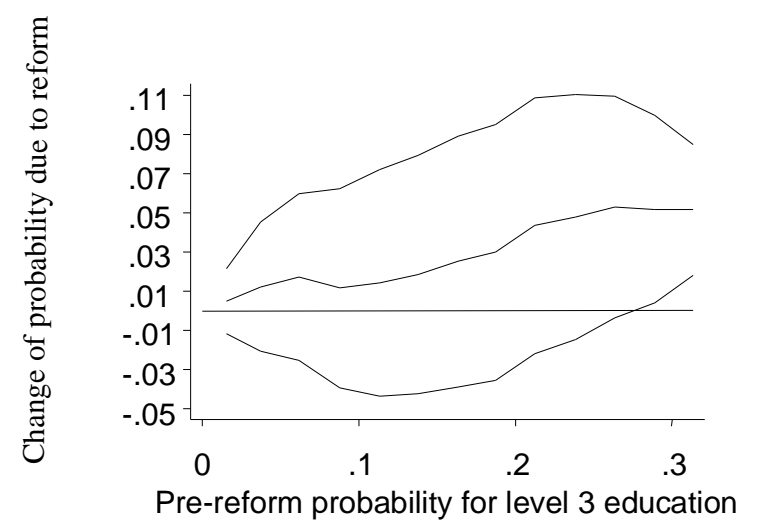

Figure 3: Predicted post-reform change in the probability of obtaining education level 3. 


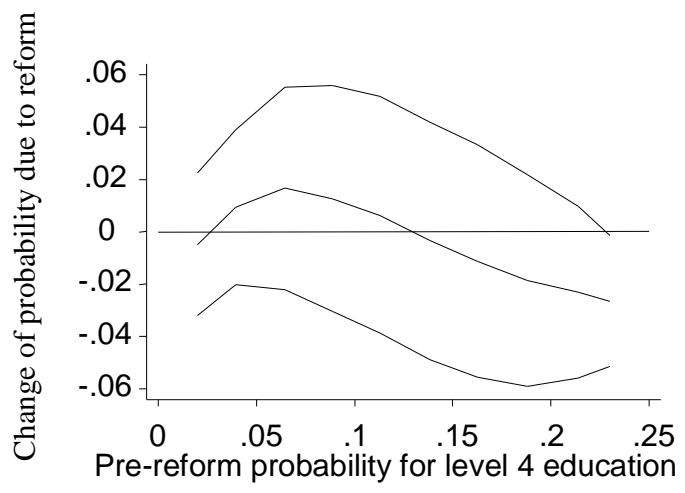

Figure 4: Predicted post-reform change in the probability of obtaining education level 4 .

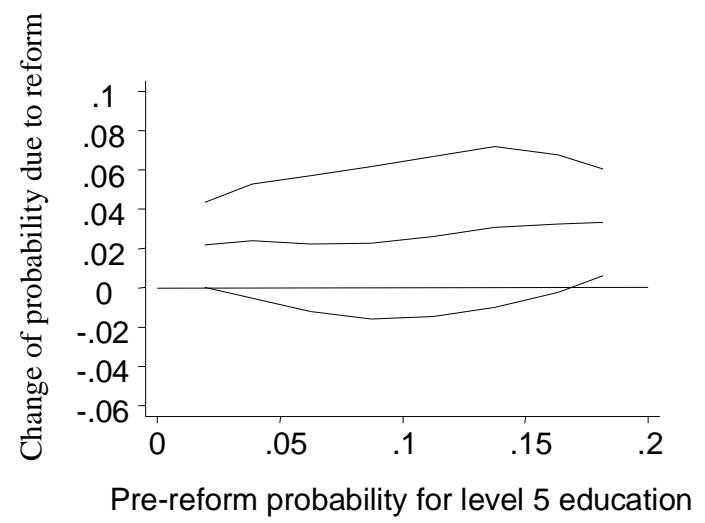

Figure 5: Predicted post-reform change in the probability of obtaining education level 5. 


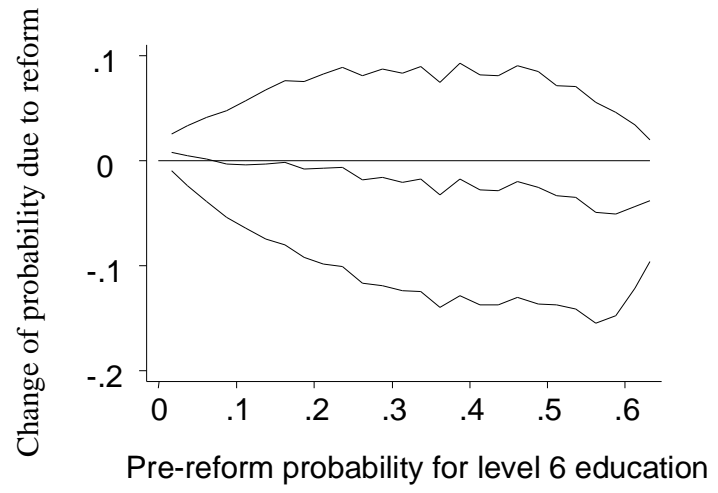

Figure 6: Predicted post-reform change in the probability of obtaining education level 6.

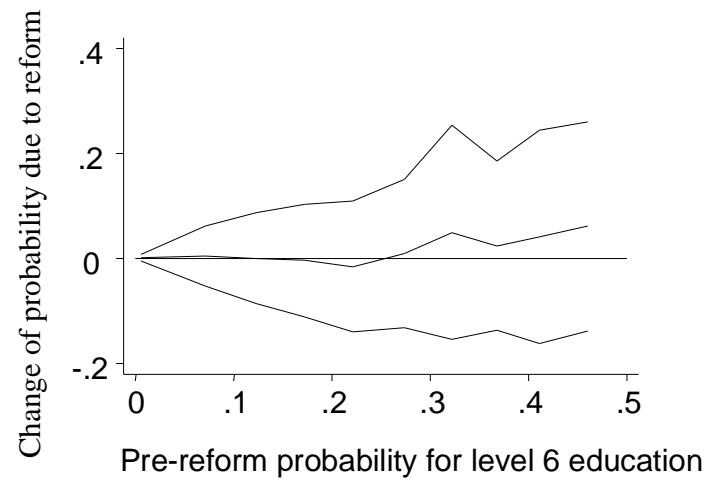

Figure 7: Predicted post-reform change in the probability of obtaining education level 7. 
relate more to vocational type training. These are levels 3 and 5 . For level 3 there is a significant overall effect of the reform and this is driven primarily from those who had a relatively high pre-reform probability to switch; a significant proportion of these people were induced to switch as a result of the reform. For level 5 again the effect is larger for those with a higher pre-reform probability. There is also a negative and marginally significant effect of the reform for level 4 for those with the highest probabilities pre-reform of attending that level. These individuals may be continuing their schooling to level 5 post reform. However, as expected, the reform had no effect at all on University attendance (levels 6 and level 7). The effect is quite clearly zero. The reform does not allow us to identify the effects of the two highest levels of education.

The fact that the reform had an effect beyond the change in the statutory level of schooling has a number of possible explanations: As is described in Section 2, one of the aims of the reform was to facilitate transition to secondary and higher education. Post reform access to higher levels of education was made easier by reducing selection. Thus those who were not allowed to continue to Junior secondary school in the prereform regime were not able to continue on Upper secondary school. As shown in Table 2 this group was almost 20 percent of those who followed the pre-reform system. Post reform such restrictions were removed. It is also worth recalling that individuals who were from disadvantaged backgrounds received financial assistance to continue schooling up to the comprehensive school. This may have created a secondary knock on effect through a wealth effect from the financial assistance, although we are not in a position to bring direct evidence on this matter. ${ }^{21}$ Finally, the knock on effect may reflect a response to an anticipated general equilibrium effect of the reform: If it is the case that the returns to level 2 fall as a result of the large influx of those who were previously in level 1, then the relative benefit to continuing to level 3 say, is increased.

\footnotetext{
${ }^{21}$ This point is of great importance for countries such as the UK who are currently introducing a special allowance (EMA) for encouraging school continuation.
} 
The response of those assigned to the reform during the experiment to such a general equilibrium effect could have been different due to the grants offered and due to the greater ease with which higher education could be obtained post reform.

The ordered probit results also show that the principal components measuring Ability as well as the Father's education level has a strongly significant influence on choice of qualification level. The coefficient estimates for the Father's education indicator variable shows that people with highly educated fathers are more likely to obtain a higher education level also when controlling for ability. Also, the sign on the principal components for intellectual ability shows that individuals with higher intellectual ability are more likely to choose higher qualification levels.

To sum up, assignment to the reform did in fact have a significant effect on the average years of schooling and level of education achieved, beyond the change in the statutory level.

\subsection{The Effect of education on earnings}

In what follows we present two set of results. The first uses the smaller SLLS survey and examines the returns to years of education. The second uses the larger IS survey and examines the returns to qualifications. In both cases we use OLS as well as allowing for the endogeneity of educational choices using the reform assignment as an instrument. Finally we investigate the way the returns to education vary with observed ability.

\subsubsection{The returns to years of education}

In Table 3 we present results for OLS regressions based on the SLLS survey. All regressions include cohort and county indicators and the dependent variable is log annual earnings in 1991. We attempt a number of experiments. In all cases the returns are estimated to approximately $3 \%$ for each year of additional education. Thus in column B we include father's education. Although this has a significant effect 


\begin{tabular}{lcccc}
\hline \hline & $\mathrm{A}$ & $\mathrm{B}$ & $\mathrm{C}$ & $\mathrm{D}$ \\
\hline Years of Education & 0.0284 & 0.0278 & 0.0285 & 0.0288 \\
& 0.0072 & 0.0068 & 0.0066 & 0.0069 \\
Father Vocational & & 0.0001 & 0.0027 & 0.0009 \\
& & 0.0335 & 0.0337 & 0.0340 \\
Father Upper Secondary & & -0.1271 & -0.1225 & -0.1214 \\
& & 0.1032 & 0.1023 & 0.1042 \\
Father University/College & & 0.1633 & 0.1701 & 0.1699 \\
& & 0.0495 & 0.0508 & 0.0483 \\
reform & & & -0.0457 & \\
& & & 0.0392 & \\
reform (place of birth) & & & & -0.0759 \\
& & & & 0.0536 \\
\hline
\end{tabular}

Notes: Dependent variable is log annual earnings in 1991. Default group of father's education is statutory education. Asymptotic standard errors in italics. Cohort and regional dummies included. Default group of father's education is statutory education. Sample size: 427 .

Table 3: OLS estimates of the returns to years of education. Swedish Level of Living Survey.

on earnings of the child it does not seem to have any impact on the estimated returns. In the next two columns (C and D) we include as regressors two separate reform indicators. In column $\mathrm{C}$ we include a variable indicating whether the individual was educated in the reformed school system. Assuming education is exogenous for wages, this measures any overall quality effects of the reform on earnings. In Column $\mathrm{D}$ we include an indicator for reform assignment, based on where the individual was born. Although quite large, the coefficients on both reform indicators are insignificant and their inclusion has no effect on the estimated returns to education. As we shall see this result is confirmed by the results in the much larger IS survey where the coefficient on the reform indicator is much smaller and much more precisely estimated.

In Table 4 we present estimates of the model allowing for education to be endogenous to wages. The instrument is whether the individual was born in a municipality which implemented the reform for that birth cohort. 
The first column (E) reports the results from a simple Instrumental Variables model. We implement it by adding the residual from the regression of education on the reform assignment indicator and all other exogenous variables in the model. ${ }^{22}$ The point estimate is $3.56 \%$ annual return to education for these cohorts (1945-1955) in 1991.

The second column presents the results for the random coefficients model. To estimate the model we simply include the interaction between the education level and the residual from the education reduced form. The additional term will be significant if individual returns to education are heterogeneous and if individuals have information on their particular returns when making their education choices. In the case of the random coefficients model the average returns are estimated to be higher at $3.71 \%$. If the reform had the effect of pushing lower ability individuals into higher education levels we would expect that correcting for unobserved ability could increase the estimated returns vis a vis OLS on the entire sample. However, neither of two the estimates are significantly different from OLS. In both cases the exogeneity tests do not reject the OLS results: For the IV model the hypothesis of exogeneity is accepted with a p-value of $72 \%$; in the random coefficient model the p-value is about $11 \%$.

Finally, wage growth may depend on education. Hence in both the OLS and the IV/random coefficients regression we included an interaction of the years of education with cohort. In all cases this was completely insignificant. This is not surprising given the age of the youngest person in the sample is 46 and the eldest is 56 . At this age, earnings growth is very low (see e.g. Edin and Holmlund, 1995 or Meghir and Whitehouse, 1996).

In conclusion, we find returns to education of approximately $2.8 \%$ with OLS and $3.6 \%$ with IV or random coefficients. Allowing for endogeneity of year of education increases the estimated returns, even when we allow for random coefficients. However,

\footnotetext{
${ }^{22}$ This gives numerically identical results to Instrumental Variables. However this implementation has the advantage that the t-value of the residual is an exogeneity test for education.
} 


\begin{tabular}{lcc}
\hline \hline & $\mathrm{E}$ & $\mathrm{F}$ \\
\hline Years of education & 0.0356 & 0.0371 \\
& 0.0214 & 0.0213 \\
Father Vocational & -0.0099 & -0.0022 \\
& 0.0457 & 0.0466 \\
Father Upper Secondary & -0.1432 & -0.1476 \\
& 0.1207 & 0.1190 \\
Father University/College & 0.1255 & 0.0908 \\
& 0.1175 & 0.1163 \\
Edres & -0.0080 & 0.0493 \\
& 0.0230 & 0.0381 \\
Educ * Edres & & -0.0042 \\
& & 0.0021 \\
Exogeneity test (p-val) & $0.16(72.5 \%)$ & $5.2(11.2 \%)$ \\
\hline Notes as in Table 3 & &
\end{tabular}

Table 4: IV estimates of the returns to years of education. Swedish Level of Living Survey.

the results are not significantly different from OLS, despite the fact that our instrument is very informative.

\begin{tabular}{|c|c|c|c|c|c|c|}
\hline & \multicolumn{2}{|c|}{ A } & \multicolumn{2}{|c|}{ B } & \multicolumn{2}{|c|}{$\mathrm{C}$} \\
\hline & $\widehat{\beta}$ & $s_{\widehat{\beta}}$ & $\widehat{\beta}$ & $s_{\widehat{\beta}}$ & $\widehat{\beta}$ & $s_{\widehat{\beta}}$ \\
\hline Comprehensive/Junior Secondary & 0.0480 & 0.0196 & 0.0131 & 0.0197 & 0.0129 & 0.0197 \\
\hline Vocational & 0.0904 & 0.0170 & 0.0528 & 0.0172 & 0.0517 & 0.0172 \\
\hline Upper Secondary & 0.2239 & 0.0179 & 0.1560 & 0.0186 & 0.1526 & 0.0186 \\
\hline Post Upper Secondary $\leqslant 2$ years & 0.3081 & 0.0191 & 0.2273 & 0.0201 & 0.2217 & 0.0202 \\
\hline University/College & 0.4822 & 0.0192 & 0.3792 & 0.0209 & 0.3672 & 0.0212 \\
\hline Ph.D. & 0.6712 & 0.0415 & 0.5467 & 0.0430 & 0.5244 & 0.0436 \\
\hline 1953 cohort & -0.0520 & 0.0096 & -0.0615 & 0.0097 & -0.0629 & 0.0097 \\
\hline Father Vocational & & & & & 0.0103 & 0.0204 \\
\hline Father Upper Secondary & & & & & 0.0513 & 0.0219 \\
\hline Father University/College & & & & & 0.0691 & 0.0281 \\
\hline Ability (p-value) & \multirow{2}{*}{\multicolumn{2}{|c|}{$15.7 \%$ coef: -0.0156}} & \multicolumn{2}{|c|}{$0 \%$} & \multicolumn{2}{|c|}{$0 \%$} \\
\hline $\begin{array}{l}\text { Test for Excluded } \\
\text { Reform Indicator } \\
\text { Joint significance of } \boldsymbol{\lambda} \text { (p-value) }\end{array}$ & & & \multicolumn{2}{|c|}{$40.8 \%$ coef: -0.0093} & \multicolumn{2}{|c|}{$35.1 \%$ coef: -0.0105} \\
\hline Annual returns & \multicolumn{2}{|c|}{$5.8 \%$} & \multicolumn{2}{|c|}{$4.8 \%$} & \multicolumn{2}{|c|}{$4.5 \%$} \\
\hline
\end{tabular}

Table 5: Education returns. Results from OLS 


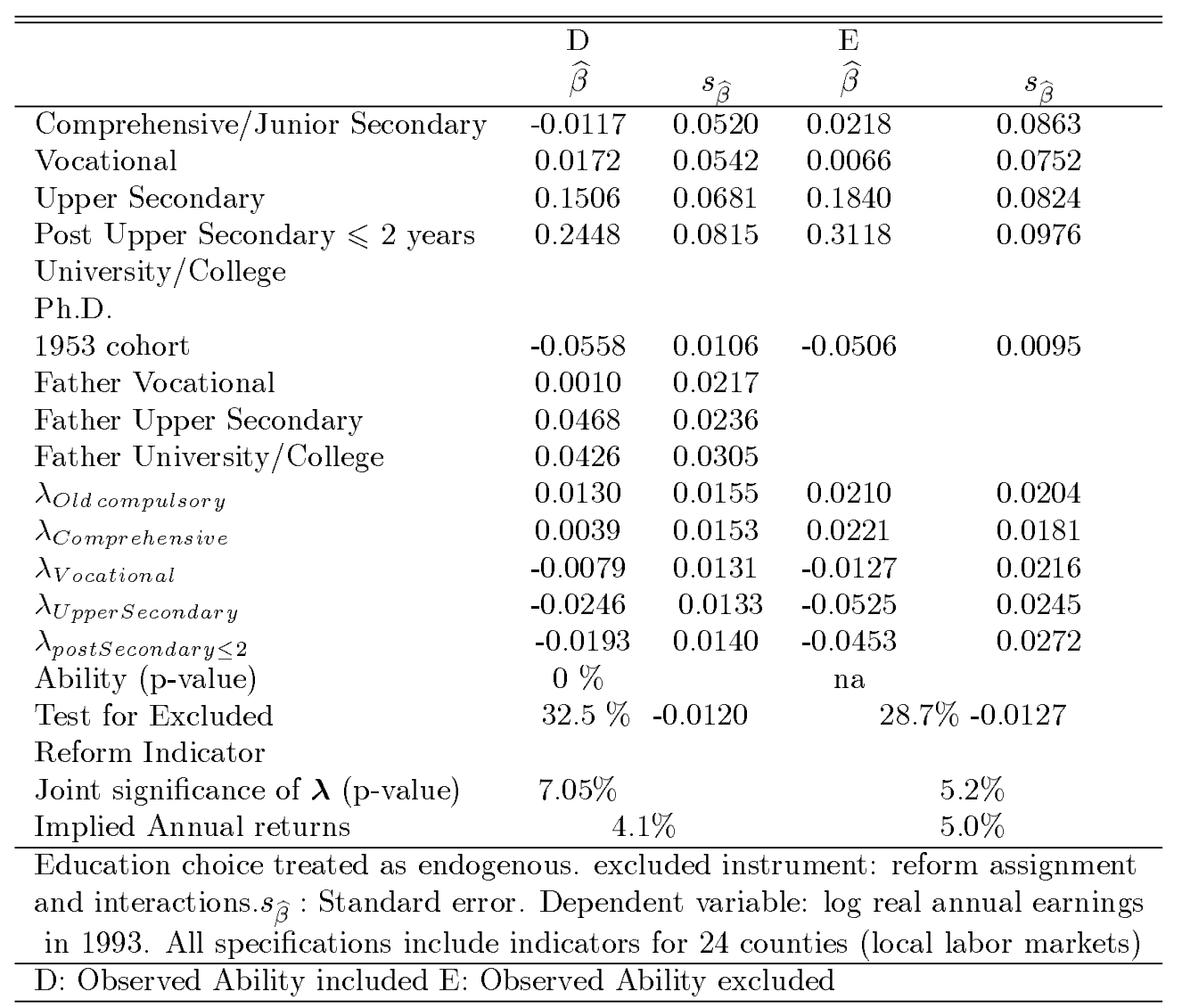

Table 6: Education returns. Results from model that alow for selection on unobservables.

\subsubsection{The returns to qualifications}

We now turn to the results using the qualifications obtained by the individual. This uses the data from the IS survey. As before the dependent variable is log annual earnings in 1993. All regressions include indicators for the county of residence and a cohort indicator for the 1953 cohort (there are only two birth cohorts in this data 1948 and 1953). In all regressions the 1953 cohort is shown to have wages which are about $5.5 \%$ lower. This is a combination of a cohort and age effect. In all cases the reference level of education was the pre-reform statutory school. 
Qualification Choice is exogenous In column A of Table 5 we present the results from a simple OLS regression with no other controls. This implies a $5 \%$ return to attending the Comprehensive/Junior secondary school and completing school at 16,9\% return for a vocational education, $22 \%$ for Upper secondary school, $48 \%$ for University and $67 \%$ for a Ph.D. If one imputes the average number of years of education corresponding to each qualification level these results imply a 5.8\% annual return to education. This is higher than the returns estimated before, perhaps because it allows for the non-linear effects due to qualifications.

In column B we include the principal components from the ability scores described in Section 4 and in the Appendix. We include the first 20 principal components to summarize ability in the education regressions as no principal component beyond that had any explanatory power. The results presented in column B demonstrate very strong effects on the estimated returns of including ability indicators, without a significant increase in the standard errors. In particular, given for now that all selection is on observables and that the returns are homogeneous there seems to be a very low and insignificant return to completing the comprehensive school vis a vis the old system's compulsory level. Even the third level vocational schooling only has a $5 \%$ return. The returns to all other levels of qualification relative to the basic level are lower. Moreover the increments from one level to the next also fall. For example the premium for university education over and above high school is estimated to be $26 \%$ in column $\mathrm{A}$ and it falls to about $22 \%$ in column $\mathrm{B}$. Thus these result show strong evidence that ability does affect earnings and omitting it can generate serious upwards ability bias in the estimated returns to qualifications. Note finally that the indicator for reform is still insignificant and even lower than before.

In column $\mathrm{C}$ we also include father's education. This leads to a further very small reduction in the returns. Overall, workers with better educated fathers have an earnings advantage. The most significant association comes from having a father who attended University, which is associated with a $7 \%$ earnings advantage, conditional 
on qualifications and ability. Once we control for ability and father's education, the implied annual returns to education fall to $4.5 \%$.

In all cases we have tested whether the reform had an effect over and above the observed level of attainment. In all cases the effect of the reform indicator is very small (-1\% in column C) and always completely insignificant.

To sum up, these results show quite convincingly that ability bias is an important issue when considering the returns to education, at least relating to observable ability indicators.

Using the reform to control for endogenous qualification choice We now turn to the results that control for endogenous qualification choices. We use the reform assignment as the source of exogenous variation.

The results are in columns $\mathrm{D}$ and $\mathrm{E}$ of Table 6 . In column $\mathrm{D}$ we include the observed ability indicators while in column $\mathrm{E}$ we exclude them (as well as excluding father's education). In analysing the effects of the reforms on attainment we showed that it had no significant impact on attendance in the last two levels education. Hence, we do not report results referring to these two levels since they are not identified by the reform. Of the results we do present, the returns to the fourth and fifth levels may be subject to the weak instrument bias. However, we have shown that even for these groups there is a marginally significant impact of the reform on attainment for those who were initially likely to achieve that level. The estimates we do report relate to $81 \%$ of the sample.

The estimated returns for levels 2 and 3 are lower from those reported in column $\mathrm{C}$ of Table 5; however there is an increase in the estimate of the return for the 5th level (short college/post secondary school). The returns to the comprehensive school have become negative; it is quite conceivable that on average individuals who attend the comprehensive school versus stopping earlier waste more in experience than they gain in human capital. Nevertheless, we can't make much of this since the change 
from OLS is not significant. The vocational school returns have also fallen further to $1.7 \%$. In these results the effect of the father's education is slightly less important. On average for the first five levels the implied average annual return to education over the included education categories is $4.1 \%$ which should be compared to an average of $3.65 \%$ for the same regression estimated by OLS (i.e. not taking into account the two highest categories).

Turning to column $\mathrm{E}$ we see that the results are quite similar even if we do not include the observed ability indicators. ${ }^{23}$ Hence just using the reform corrects for the ability bias apparent when we compare to the results in column A. However, including the ability indicators has the advantage of increasing the precision substantially.

At the bottom of Table 6 we also report the coefficient estimates of the selection terms into each of the five educational categories for which we report estimates (i.e. excluding the two University categories). We can use them, together with the residual terms to obtain estimates of the effects of education given knowledge that the individuals choose the particular qualification ("the effect of treatment on the treated"). Using the estimates from column D of Table 6, the effect of treatment on the treated for the comprehensive school vis a vis the old compulsory school is 0.011 and for the vocational school 0.025 both of which are higher than the returns obtained for a randomly assigned individual. ${ }^{24}$ The latter is, however, still smaller than the returns from OLS. Thus the point estimates are consistent with self-selection on the basis of unobserved returns to qualifications.

The test of exogeneity of education choice does not reject the hypothesis strongly. The joint significance of the five selection terms has a p-value of $7 \%$ as reported in the table. In any case, even if we were to conclude that exogeneity is rejected, the results

\footnotetext{
${ }^{23}$ When they aree excluded from the regression they are also excluded from the instruments.

${ }^{24}$ The effect of treatment on the treated is defined by $E(\ln w \mid e d=s$ and $d=s)-$

$E(\ln w \mid e d=1$ and $d=s)$ where $e d$ is the actual level achieved and $d$ is the desired level. So $E(\ln w \mid e d=1$ and $d=s)$ represents the counterfactual expected wage for those known to have chosen education level $s$. We compute it as the estimated return for level $s$ plus the difference in the selection coefficients for level $s$ and level 1 multiplied by the average selection terms for level $s$.
} 
from the two methods do not have widely different implications, when we control for observed ability in the OLS results. Low qualifications seem to have hardly any return over and above the impact of ability on pay.

Finally note that assignment to the reform has no significant impact in either the OLS results or in the ones where we control for self-selection. The effect on earnings of reform assignment (given qualifications) is around $-1 \%$ and completely insignificant in all cases. ${ }^{25}$ Hence the other aspects of the reform do not seem to have had a significant impact over and above the impact of the reform on the qualification level reached. This operated both through changes inn the statutory minimum and through financial assistance.

\subsubsection{The effect of observed ability on the returns to qualifications}

The final issue we consider is how the returns to qualifications vary with observed ability. The results presented in columns D and E of Table 6 allow for ability differences in the returns when estimating the average returns. However now we include explicitly the interactions of the ability scores with qualifications.

In Table 7 we report the results of allowing the returns to qualifications to vary with the first principal component of the ability indicators. No other interactions were significant. ${ }^{26}$ The regressions also include county indicators, the 20 first principal components of ability, the father's education and an indicator for the 1953 cohort.

As far as the mean returns are concerned (i.e. at average ability which is normalised to zero), presented under the $\delta_{0}$ column, the main difference with the earlier results is that the incremental return of attending University vis a vis Upper secondary school or Short post upper secondary education has fallen by four percentage

\footnotetext{
${ }^{25}$ In the case of the results of column D Table 6 the direct impact of the reform indicator is identified to the extent that the reform had differential impact on the two cohorts we include in the analysis, over and above a pure cohort effect. We find little evidence of such a differential impact.

26 The interpretation of the first principal component is thus of some importance for this analysis. As can be seen in the Appendix, in which we report the coefficient estimates of the first three principals, the interpretation of the first PC is straight forward: It gives positive, and increasing, weight to high ability scores and negative, and decreasing, coefficients to low ability.
} 
points. Moreover, the mean returns for the Comprehensive/Junior secondary school and Vocational school have risen with respect to the pre-reform statutory schooling level. Taken together, this is strong evidence of a complementarity between ability and education. The coefficients $\delta_{1}$ show how the returns to qualifications vary with ability. ${ }^{27}$ The test statistic for homogeneous returns is 23.16 and the p-value is $0\left(\chi_{6}^{2}\right)$. In column $\mathrm{G}$ we repeat the estimation using the reform assignment as an instrument. We would not expect the average returns to change much vis a vis the results in column E of Table 6 and in fact they are quite similar.. Moreover the $\delta_{1}$ coefficients are lower for the two lower education levels as in the case of OLS. However, the estimates are too imprecise now.

Turning to the implications from OLS, for the lower levels of education the gradient of the returns by ability $\left(\delta_{1}\right)$ are not very high in absolute terms. However very able individuals can obtain returns nearly double those with average ability. Nevertheless the effect is not that significant. For those attending Upper secondary school or above the returns increase quite rapidly in absolute terms with respect to ability. An individual at the top of the ability distribution attending University can earn 20 percentage point more than someone with average ability. The effect is even steeper for the small group of graduates ( $1.1 \%$ of the sample).

Taking into account the fact that the higher the ability score the higher the probability of increased education, we see that the results are consistent with a simple model of self selection by comparative advantage: Higher ability people can command higher than average returns with Upper secondary school or University education and are thus over-represented in these groups.

The other interesting aspect of these results are that higher ability people have an absolute and comparative advantage at all education levels. We found that no other ability indicator apart from the first principal component was at all significant.

\footnotetext{
${ }^{27}$ The percentiles for the ability variable are $1 \%-3.02,5 \%-2.61,10 \%-2.35,25 \%-1.71,50 \%-.211$, $75 \% 1.53,90 \% 2.88,95 \% 3.42,99 \% 4.06$
} 


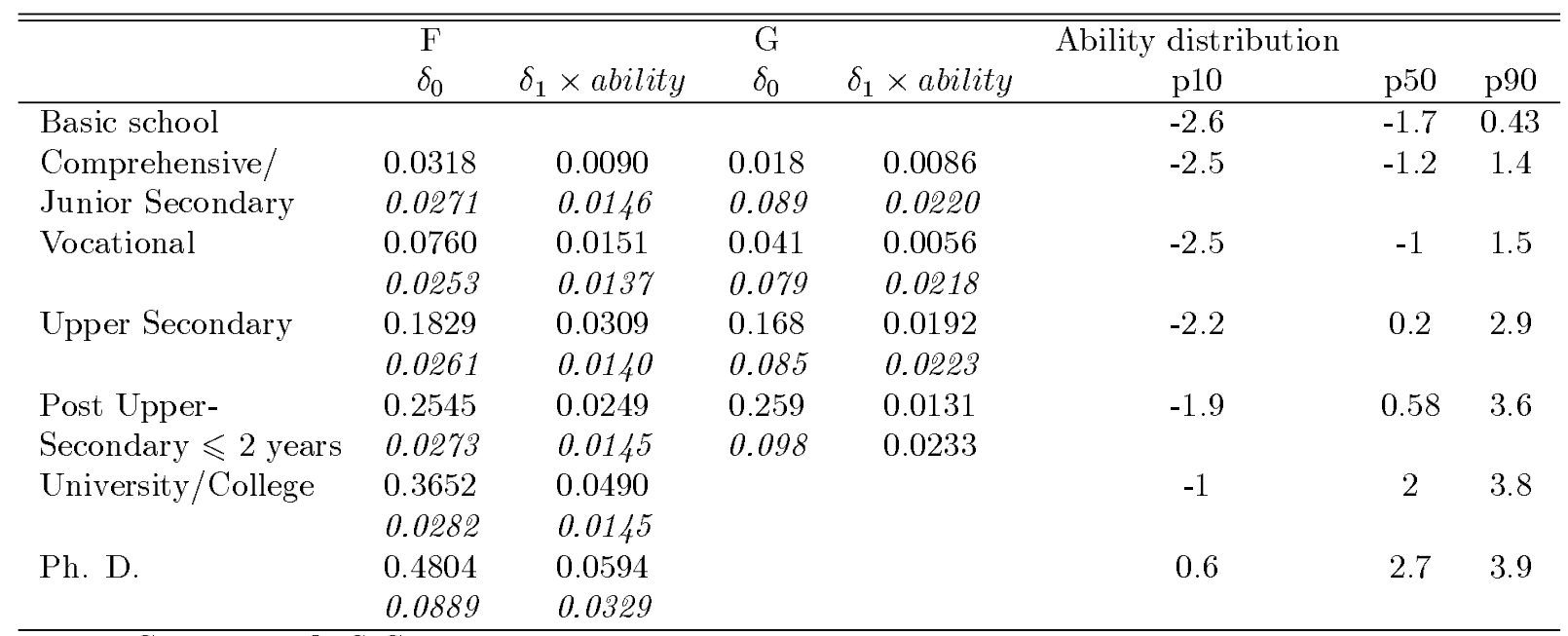

Notes:Column F: OLS Column E: Education treated as endogenous. Dependent variable is annual earnings in 1993. Also Included: County indicators, the 20 first principal components of ability, the father's education and an indicator for the 1953 cohort.

Table 7: The returns to qualifications when returns vary by observed ability.

The last three columns of Table 7 show the lowest decile, the median, and the upper decile of the distribution of the ability indicator we use. They show very strong selection effects by ability on education choices. However, it is still the case that there is plenty of heterogeneity within each group. Amongst other things, this may reflect heterogeneous costs and tastes for education and of course lack of perfect prior knowledge by individuals of the effect of ability on the returns to education. 


\section{Conclusions}

In this paper we first examine the impact of the Swedish education reform on educational choices using a unique social experiment conceived to evaluate the reform. We find that the reform had a significant impact on the number of years of education. The reform definitely had a very strong impact at the lower end; it seems that the individuals not assigned to the reform obtained significantly less education. Moreover, we also found that some of the impact can be attributed to a secondary knock on effect: Controlling for cohort, region and ability we find that individuals assigned to the reform were more likely to obtain vocational qualifications (level 3 and level 5) which certainly exceeds the minimum education prescribed by the reformed system.

We use the reform to assess the returns to education by comparing the earnings of those assigned to the reformed system and those not for 1993, relative to the impact of the reform on years of education. We find that the results obtained using the exogenous variation induced by reform assignment led to point estimates higher than OLS, even when we allow for heterogeneous returns to years of education. This is similar to results by other studies that also have used exogenous variation to control for endogeneity of education. ${ }^{28}$ It is also consistent with the idea that the reform changed the composition of those taking higher education post reform towards lower average ability. However, exogeneity of education cannot be rejected.

We then proceed using a much larger sample to examine the returns to qualification, allowing for the returns to be heterogeneous across individuals due to unobservable characteristics. Since the reform had no impact on University attendance (levels 6 and 7 ) we only estimate the returns to levels $2-5$ relative to the old compulsory school using the reform. We find that the average returns to level 2 and 3 (the new compulsory level and the lower vocational one) are very low or zero. The implied effects of treatment on the treated are higher, implying the results are consistent with

\footnotetext{
${ }^{28}$ See e.g. Angrist and Krueger (1991 and 1992), Butcher and Case (1994), Card (1993), Harmon and Walker (1995), Kane and Rouse (1993).
} 
a self-selection by ability - those who do select into these levels have positive returns. We also show that controlling for ability using reform assignment or by including a rich set of observed ability indicators gives similar results. However, ignoring self-selection by ability overestimates the returns to education.

We subsequently show that the returns vary with observed ability and that the data is consistent with self-selection by comparative advantage: The higher ability individuals are better at all levels of qualifications in both absolute and relative terms.

Furthermore, we present evidence that the effect of the reform operated through the amount of education obtained by individuals and not through other direct effects such as changes in quality or other practices in schools. We do not detect any significant independent effect of the reform on earnings, given education. This is true in all results we consider.

Our results are very much in line with what has been obtained in two previous studies on Swedish data. Kjellström (1997) obtain estimates of a positive ability bias when observable ability measures are included in the OLS wage equations. A study on a large sample of twins, Isacsson (1999), also get results pointing in that direction: The returns to the within twin-pair differences in education are lower than the corresponding OLS estimates.

Overall therefore the reform package did increase the education level of the cohorts affected by the transition. Whether this accelerated an already existing trend or whether it affected future cohorts as well is not clear. A particularly interesting result is that the reform had effects beyond those who switched from one compulsory level to another. The financial assistance offered by the government may have had an effect in this respect. We have also shown that the increased education had positive returns on average, particularly if we take the OLS results that are not rejected in any specification. So the reform does seem to have had positive effects in terms of final outcomes as well. ${ }^{29}$ It is possible that the reform did have other secondary effects on

\footnotetext{
${ }^{29}$ In future research we intend to attempt to recover earnings for more than one year for both
} 
e.g. income inequality, employment security and criminality. It also implied several different costs. Whether the estimated returns justify the costs of the reform cannot be evaluated from our data. A full Cost-benefit analysis of the Swedish 1950 education reform is left for further research. However, assessing the private economic returns to additional compulsory education seems like a natural first step in such analysis.

cohorts for a further examination of the returns. 


\section{Appendix}

This Appendix describes the data used from the Swedish Level of Living Survey as well as the IS survey. The IS survey consists of information from four main sources:

(1) Student's social background and socio-economic situation. The information from this block of the data-set is obtained directly from the respondent through the survey questionnaire. The variables measuring mother's and father's education are grouped into four levels: Basic education ("folkskola"), Junior secondary school ("realskola/flickskola"), Upper secondary school ("gymnasium") and Academic education.

(2) Results from IQ and achievement tests. The IS surveys contains results from two types of tests: (a) Results from three different types of IQ tests; (b) Results from test on achievement in different subjects taught in school. By construction, all test scores are comparable between the 1948 and the 1953 cohort surveys (see Härnqvist and Svensson, 1973).

(a) IQ tests. The three different IQ tests measure three different aspects of intellectual ability. First, the verbal ability is measured by the test Opposite (The respondent is asked to choose the opposite of a word from four given choices). Second, the spatial ability is measured with the test Metal folding (The respondent is asked to choose which three dimensional object from four given alternatives that can be obtained from a given flat piece of metal). Third, the mathematical ability is measured through the test Number series (The respondent is asked to complete a given series of numbers).

(b) Achievement tests. The ability in reading, writing, English, and mathematics, all subject taught in the compulsory school, are measured by standardized tests.

It is important to note that the data were collected before any of the students in the sample were able to choose between, or be selected into, different levels of education. That is, the test scores should not be seen as an outcome of an educational choice. ${ }^{30}$

(3) Register information on the students performance and type of school. Data on

\footnotetext{
${ }^{30}$ This facilitates the use of this kind of information in the estimation of the rate of returns to education (see e.g. Angrist \& Krueger, 1998).
} 
grades were obtained by matching the samples with a national register provided by the National School Board. In the pre-reform grade system the grades were set in seven levels, while the post-reform school applied a five level scheme. These grading scheme were made comparable by transforming the highest and lowest two levels in the pre-reform scheme to the highest and lowest level respectively in the post-reform scheme. The National School Board register also provided information on the type of school attended, i.e. whether or not the student followed the new, post-reform school system.

(4) Information from the National tax and the National education registers. Data on several variables were obtained when the samples from 1961 and 1966 were matched with the National tax and National education registers from 1993. These registers contain administrative records for all Swedish citizens. Data for the dependent variable, log earnings, are measured as the log of annual (1993) earning from labour obtained from individual tax returns. The National tax register also contains data on employment status and whether or not each individual were self employed in 1993 - variables that we use for selecting the sample used for estimation.

Table 1 gives descriptive statistics of the included variables from the IS survey.

The IS survey contains a rich set of measures of intellectual ability. Table 2 gives descriptive statistics of these variables.

Figure 1 shows the cumulative share of the total variance accounted for by a given number of principal components. From this figure it is evident that the number of variables included may be reduced substantially without losing much of the total variance in the variables measuring intellectual ability.

Table 3 shows the PC loadings for the first three principal components as well as the percentage share of the total variance that each of these principal components account for. It is evident from the results shown in Table 3 that the first PC, Abil1, 


\begin{tabular}{|c|c|c|c|}
\hline Variable & Description & Mean & s.e. \\
\hline LnWage & Log of annual labor earnings in 1993 & 7.626 & 0.454 \\
\hline D53 & Indicator for 1953 cohort & 0.448 & 0.497 \\
\hline Reform & Indicator for education reform assignment & 0.554 & 0.497 \\
\hline Level1 & Pre-reform compulsory school 7 or 8 years & 0.093 & 0.290 \\
\hline \multirow[t]{2}{*}{ Level2 } & Post-reform compulsory school or pre-reform & 0.154 & 0.361 \\
\hline & Junior secondary school & & \\
\hline Level3 & Upper secondary school $\leqslant 2$ years & 0.275 & 0.447 \\
\hline Level4 & Upper secondary school $\geqslant 3$ years & 0.163 & 0.370 \\
\hline Level5 & Post upper secondary school $\leqslant 2$ years & 0.126 & 0.331 \\
\hline Level6 & Post upper secondary school $\geqslant 3$ years & 0.176 & 0.381 \\
\hline Level7 & Higher academic degree ( $\mathrm{PhD}$ or Licentiate) & 0.013 & 0.115 \\
\hline \multicolumn{4}{|c|}{ Father's Education Levels } \\
\hline $\mathrm{Fe} 1$ & Basic compulsory level (6 years) & 0.792 & 0.406 \\
\hline $\mathrm{Fe} 2$ & Junior secondary school & 0.074 & 0.262 \\
\hline $\mathrm{Fe} 3$ & Upper secondary school & 0.061 & 0.240 \\
\hline $\mathrm{Fe} 4$ & University & 0.037 & 0.188 \\
\hline County 1 & Stockholm & 0.185 & 0.388 \\
\hline County 2 & Uppsala & 0.033 & 0.180 \\
\hline County 3 & Södermanland & 0.028 & 0.166 \\
\hline County 4 & Östergötland & 0.049 & 0.215 \\
\hline County5 & Jönköping & 0.035 & 0.183 \\
\hline County 6 & Kronoberg & 0.022 & 0.147 \\
\hline County 7 & Kalmar & 0.026 & 0.160 \\
\hline County 8 & Gotland & 0.006 & 0.076 \\
\hline County 9 & Blekinge & 0.016 & 0.124 \\
\hline County 10 & Kristianstad & 0.031 & 0.173 \\
\hline County 11 & Malmöhus & 0.085 & 0.279 \\
\hline County 12 & Halland & 0.032 & 0.177 \\
\hline County 13 & Göteborg och Bohuslän & 0.082 & 0.275 \\
\hline County 14 & Älvsborg & 0.050 & 0.218 \\
\hline County 15 & Skaraborg & 0.031 & 0.174 \\
\hline County 16 & Värmland & 0.038 & 0.191 \\
\hline County 17 & Örebro & 0.030 & 0.170 \\
\hline County 18 & Västmanland & 0.027 & 0.163 \\
\hline County 19 & Kopparberg & 0.036 & 0.186 \\
\hline County 20 & Gävleborg & 0.034 & 0.182 \\
\hline County 21 & Västernorrland & 0.032 & 0.175 \\
\hline County 22 & Jämtland & 0.017 & 0.131 \\
\hline County 23 & Västerbotten & 0.036 & 0.187 \\
\hline County 24 & Norrbotten & 0.038 & 0.190 \\
\hline
\end{tabular}

Table 1: Descriptive statistics of the variables included from the 1948 and 1953 cohort IS survey. 


\begin{tabular}{lccccc}
\hline \hline & Mean & s.e. & Min & Max & N \\
\hline Verbal IQ (Opposites) & 21.113 & $\mathbf{6 . 7 8 9}$ & $\mathbf{0}$ & 40 & 7,643 \\
Spatial IQ (Metal Folding) & 22.299 & 7.506 & 1 & 40 & 7,643 \\
Mathematical IQ (Number Series) & 20.391 & 8,092 & $\mathbf{0}$ & 40 & 7,636 \\
Grade, Swedish & 3.182 & 3.182 & 1 & $\mathbf{6}$ & 8,242 \\
Grade, English & 2.912 & 1.029 & $\mathbf{0}$ & $\mathbf{6}$ & 8,022 \\
Grade, mathematics & 3.167 & 1.082 & $\mathbf{0}$ & $\mathbf{6}$ & 8,214 \\
\hline
\end{tabular}

Table 2: Descriptive statistics of ability measures.

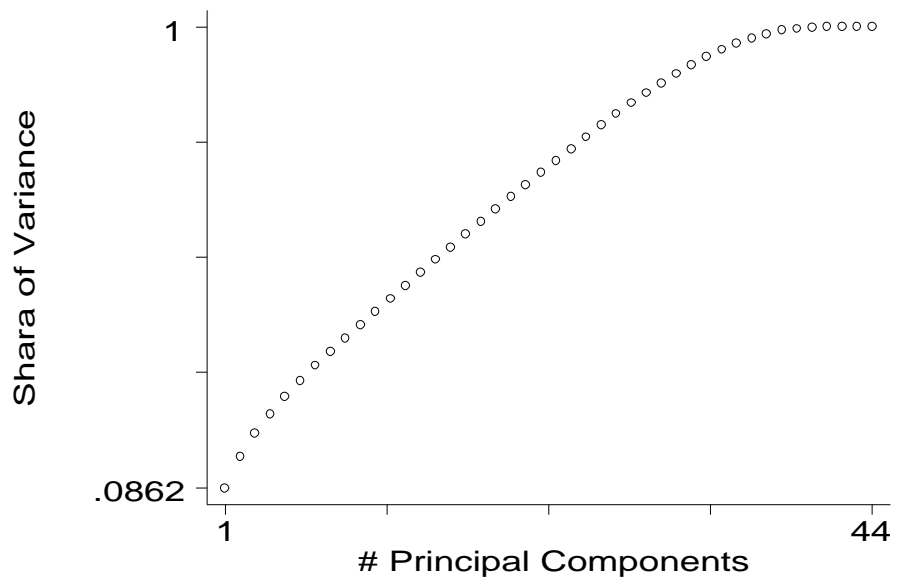

Figure 1: Cumulative share of total variance accounted for by the indicated number of principal components. 


\begin{tabular}{|c|c|c|c|c|c|c|c|}
\hline Variable/PC & Abil1 & Abil2 & Abil3 & Variable/PC & Abil1 & Abil2 & Abil3 \\
\hline \multicolumn{4}{|c|}{ Indicator Variable for score in Mathematics IQ test } & \multicolumn{4}{|l|}{ Grade in Mathematics } \\
\hline MIQ1 & -0.150 & 0.052 & 0.085 & IMG1 & -0.108 & 0.158 & 0.145 \\
\hline MIQ2 & -0.137 & -0.005 & 0.027 & IMG2 & -0.254 & 0.208 & 0.086 \\
\hline MIQ3 & -0.072 & -0.051 & 0.013 & IMG3 & -0.120 & -0.189 & -0.265 \\
\hline MIQ4 & -0.059 & -0.077 & -0.035 & IMG4 & 0.211 & -0.184 & 0.067 \\
\hline MIQ5 & 0.007 & -0.129 & 0.013 & IMG5 & 0.280 & 0.138 & 0.085 \\
\hline MIQ6 & 0.041 & -0.111 & 0.022 & IMG6 & 0.049 & 0.062 & -0.031 \\
\hline MIQ7 & 0.095 & -0.117 & 0.084 & Grade in English & & & \\
\hline MIQ8 & 0.132 & -0.055 & 0.085 & EG1 & -0.133 & 0.176 & 0.183 \\
\hline MIQ9 & 0.228 & 0.318 & -0.295 & EG2 & -0.274 & 0.206 & 0.003 \\
\hline \multicolumn{4}{|c|}{ Indicator variable for score in verbal IQ test } & EG3 & -0.026 & -0.312 & -0.329 \\
\hline VIQ1 & -0.161 & 0.080 & 0.109 & EG4 & 0.284 & -0.081 & 0.247 \\
\hline VIQ2 & -0.155 & -0.013 & -0.005 & EG5 & 0.217 & 0.175 & 0.012 \\
\hline VIQ3 & -0.081 & -0.070 & -0.027 & EG6 & 0.013 & 0.027 & -0.028 \\
\hline VIQ4 & -0.026 & -0.091 & -0.034 & Grade in Swedish & & & \\
\hline VIQ5 & -0.006 & -0.124 & -0.010 & SG2 & -0.254 & 0.285 & 0.227 \\
\hline VIQ6 & 0.039 & -0.131 & 0.036 & SG3 & -0.160 & -0.205 & -0.447 \\
\hline VIQ7 & 0.101 & -0.098 & 0.059 & SG4 & 0.276 & -0.169 & 0.253 \\
\hline VIQ8 & 0.159 & -0.050 & 0.148 & SG5 & 0.240 & 0.191 & 0.010 \\
\hline VIQ9 & 0.224 & 0.332 & -0.292 & SG6 & 0.028 & 0.039 & -0.024 \\
\hline \multicolumn{4}{|c|}{ Indicator variable for score in spatial IQ test } & Variance/total variance in \% & 8.62 & 6.19 & 4.60 \\
\hline SIQ1 & -0.128 & 0.015 & 0.057 & & & & \\
\hline SIQ2 & -0.071 & -0.032 & 0.030 & & & & \\
\hline SIQ3 & -0.045 & -0.035 & 0.060 & & & & \\
\hline SIQ4 & -0.018 & -0.065 & 0.035 & & & & \\
\hline SIQ5 & 0.001 & -0.049 & 0.047 & & & & \\
\hline SIQ6 & 0.012 & -0.075 & 0.056 & & & & \\
\hline SIQ7 & 0.046 & -0.080 & 0.037 & & & & \\
\hline SIQ8 & 0.102 & -0.053 & 0.041 & & & & \\
\hline SIQ9 & 0.165 & 0.289 & -0.338 & & & & \\
\hline
\end{tabular}

Table 3: Loadings for principal components Abil, Abil2 and Abil3. 


\begin{tabular}{llll}
\hline \hline Variable & Description & Mean & s.e \\
\hline LnWage & Log of gross hourly wage rate & 7.36 & 0.376 \\
Reform & Assignment to education reform & 0.482 & 0.500 \\
Reim & Predicted reform assignment & 0.358 & 0.480 \\
Educ & Years of Scooling & 11.97 & 3.21 \\
Coh45 & Indicator for born in 1945 & 0.070 & 0.256 \\
Coh46 & Born in 1946 & 0.101 & 0.301 \\
Coh47 & Born in 1947 & 0.089 & 0.285 \\
Coh48 & Born in 1948 & 0.087 & 0.282 \\
Coh49 & Born in 1949 & 0.082 & 0.275 \\
Coh50 & Born in 1950 & 0.096 & 0.295 \\
Coh51 & Born in 1951 & 0.094 & 0.292 \\
Coh52 & Born in 1952 & 0.087 & 0.282 \\
Coh53 & Born in 1953 & 0.052 & 0.221 \\
Coh54 & Born in 1954 & 0.059 & 0.235 \\
Coh55 & Born in 1955 & 0.098 & 0.298 \\
Father's education & & 0.724 & 0.447 \\
Fe1 & Basic compulsory level (6 years) & 0.164 & 0.371 \\
Fe2 & Vocational education & 0.278 \\
Fe3 & Gymnasium & 0.165 \\
Fe4 & University degree & \\
\hline
\end{tabular}

Table 4: Descriptive statistics for the included variables from the Swedish Level of Living Survey.

measures high ability, i.e. it gives positive weights to high IQ scores and high grades. This is not true to the same extent for Abil2 and Abil3.

Table 4 gives descriptive statistics of the included variables from the Swedish Level of Living Survey.

\section{References}

1. Angrist, J. D. and A.B. Krueger (1991) "Does compulsory Schooling Attendance Affect Schooling and Earnings?" Quarterly Journal of Economics, 106 (4), 9701014.

2. Angrist, J. D. and A.B. Krueger (1992) "Estimating the Payoff to Schooling 
Using the Vietnam-Era Draft Lottery." NBER (Cambridge, MA) Working Paper No 4067 .

3. Angrist, J. D. and A. B. Krueger (1998) "Empirical Strategies in Labor Economics" forthcoming in Orley Aschenfelter and Richard Layard, eds., Handbook of Labor Economics vol 3. Amsterdam: North-Holland.

4. Björklund, A. and R. Moffitt (1987) "The Estimation of Wage Gains and Welfare Gains in Self-selection Models", The Review of Economics and Statistics, 69, 4249.

5. Blackburn, L. M. and D. Neumark (1995) "Are OLS Estimates of Return to Schooling Biased Downward? Another Look" The Review of Economics and Statistics, 2, 217-230.

6. Butcher, K. F. and Case, A. (1994) "The Effect of Sibling Composition on Women's Education and Earnings." Quarterly Journal of Economics, 109 (3), $531-563$.

7. Cameron, S and J.J. Heckman (1998) "Life-Cycle Schooling and Educational Selectivity: Models and Choice", Journal of Political Economy, April 1998

8. Card, D. (1993) "Using Geographic Variation in College Proximity to Estimate the Returns to Schooling." NBER (Cambridge, MA) Working Paper No 4483.

9. Card, D. (1994) "Earnings, Schooling and Ability Revisited." NBER (Cambridge, MA) Working Paper No 4832.

10. Dustmann, C. and C. Meghir (1999) "Wages, Experience and Seniority", IFS Working paper 99-01.

11. Edin, P.-A. and Holmlund, B. (1995) "The Swedish Wage Structure: The Rise and Fall of Solidarity Wage Policy?" In Differences and Changes in Wage Structures, edited by R. Freeman and L. Katz. Chicago: Chicago University Press. 
12. Erikson, R. and J. O. Jonsson (1993) "Ursprung och Utbildning", SOU 1993:85. Ministry of Education: Stockholm.

13. Erikson, R. and R. Aberg (1987) "Welfare in Transition - Living Conditions in Sweden 1968-1981, Clarendon Press, Oxford.

14. Garen, J. (1984) "The Returns to Schooling: A Selectivity Bias Approach with a Continuous Choice Variable. "Econometrica, 52 (5) 1199-1218.

15. Griliches, Z. (1977) "Estimating the Returns to Schooling: Some Econometric Problems." Econometrica, 45 (1), 1-22.

16. Harmon, C. and I. Walker (1995) "Estimates of the Economic Return to Schooling for the United Kingdom." The American Economic Review, 85 (5) 1278 1286.

17. Harnqvist, K. and Svensson, A. (1973) "A Swedish Data Bank for Studies of Educational Development", Sociological Microjournal, 7, 35-42.

18. Heckman, J. J. (1996) "Identification of Causal Effects Using Instrumental Variables: Comment" Journal of the American Statistical Association,. 91, 459-62.

19. Heckman, J. J. (1997) "Instrumental Variables: A Study of Implicit Behavioral Assumptions in one Widely Used Estimator" Journal of Human Resources 32, 441-462.

20. Heckman, J. J. , R. LaLonde and J. Smith (1998) "The Economics and Econometrics of Active Labor Market Programs", forthcoming, Handbook of Labor Economics III, O. Ashenfelter and D. Card, editors.

21. Heckman, J. J. and R. Robb (1985) "Alternative Methods for Evaluating The impact of Interventions" in Longitudinal Analysis of Labor Market data, New York, NY:Wiley. 
22. Heckman, J. J. and E. Vytlacil (1998) Instrumental Variable methods for the correlated random coefficient model: Estimating the average rate of return to schooling when the return is correlated with schooling

23. Isacsson, G. (1999) "Estimates of the Returns to Schooling from a Large Sample of Twins" Labour Economics, forthcoming.

24. Kane, T. J. and C. E. Rouse (1993) "Labor Market Returns to Two- and FourYear Colleges: Is a Credit a Credit and Do Degrees Matter?" Princeton University Industrial Relations Section Working Paper \#311.

25. Kjellström, C. (1997) "Omitted Ability Bias and the Wage Premium for Schooling: New Swedish Evidence" Swedish Institute for Social Research, WP 2/1997.

26. Lang, K. (1993) "Ability Bias, Discount Rate Bias, and the Returns to Education." Mimeo, Boston University.

27. Marklund, S. (1981) Skolsverige 1950-1975: Försöksversamhet" Stockholm: Liber UtbildningsFörlaget.

28. Meghir, C. and E. Whitehouse (1996) "The Evolution of Wages in the United Kingdom: Evidence from Micro Data" Journal of Labor Economics; 14(1), January 1996, pages 1-25.

29. Quandt, R. (1972) "Methods for Estimating Switching Regressions" Journal of the American Statistical Association, 67, 306-310.

30. Westerlund, O. (1994) "Economic Influences of Migration in Sweden": Ph. D. thesis Department of Economics, University of Umea. 